Research Paper

\title{
The Neutrophil to Lymphocyte Ratio on Admission and Short-Term Outcomes in Orthogeriatric Patients
}

\author{
Alexander Fisher, ${ }^{1,2,4}$, Wichat Srikusalanukul1, Leon Fisher ${ }^{3}$ and Paul Smith ${ }^{2,4}$ \\ 1. Department of Geriatric Medicine, The Canberra Hospital, Canberra, ACT, Australia \\ 2. Department of Orthopaedic Surgery, The Canberra Hospital, Canberra, ACT, Australia \\ 3. Department of Gastroenterology, The Canberra Hospital, Canberra, ACT, Australia \\ 4. Australian National University Medical School, Canberra, ACT, Australia \\ $\square$ Corresponding author: Dr. Alexander Fisher
}

( ) Ivyspring International Publisher. Reproduction is permitted for personal, noncommercial use, provided that the article is in whole, unmodified, and properly cited. See http://ivyspring.com/terms for terms and conditions.

Received: 2016.03.03; Accepted: 2016.06.15; Published: 2016.07.05

\begin{abstract}
Aim: To investigate the association of the neutrophil to lymphocyte ratio (NLR) at admission with presence of fracture, comorbid conditions, and its prognostic value for short-term outcomes in orthogeriatric patients.

Methods: On 415 consecutive patients (mean age $78.8 \pm 8.7[\mathrm{SD}]$ years, 281 women, 255 with a non-vertebral bone fracture, including 167 with a hip fracture, HF) admitted to the Department of Orthopaedic Surgery at the Canberra hospital (2010 - 2011) data on clinical and laboratory characteristics were collected prospectively. The validation dataset included 294 consecutive patients (mean age $82.1 \pm 8.0$ years, $72.1 \%$ women) with HF.

Results: Multivariate regression revealed four variables, presence of HF, hypoalbuminaemia $(<33 \mathrm{~g} / \mathrm{L})$, anaemia $(<120 \mathrm{~g} / \mathrm{L})$ and hyperparathyroidism $(\mathrm{PTH}>6.8 \mathrm{pmol} / \mathrm{L})$, as independent determinants of admission NLR $\geq 5$.1. There was a dose-graded relationship between presence of fracture, especially HF, postoperative complications and levels of NLR categorized as tertiles. Compared to patients with NLR<5.1 (first tertile), patients with NLR 5.1-8.5 (second tertile) had a 1.8-, 3.1-, 2.6-, and 2.5-fold higher risk for presence of any fracture, HF, developing postoperative myocardial injury (troponin I rise) and a high inflammatory response/infection (CRP>100mg/L after the 3rd postoperative day), respectively, while in subjects with NLR>8.5 (third tertile) these risks were 2.6-, 4.9-, 5.9- and 4.5-times higher, respectively; subjects with NLR>8.5 had a 9.7 times higher chance of dying in the hospital compared to patients with NLR 5.1-8.5; the NLR retained its significance on multivariate analyses. The $N L R \geq 5$. 1 predicted postoperative myocardial injury with an area under the curve (AUC) of 0.626 , CRP $>100 \mathrm{mg} / \mathrm{L}$ with AUC of 0.631 and the NLR $>8.5$ predicted in-hospital mortality with an AUC of 0.793 , showing moderately high sensitivity $(86.7 \%, 80 \%$ and $90 \%$, respectively) and negative predictive value $(92.9 \%, 71.2 \%, 99.6 \%$, respectively), but low specificity. Admission NLR was superior to other, except hypoalbuminaemia, prognostic markers; combined use of both $N L R \geq 5$. 1 and albumin $<33 g / L$ only moderately increased the accuracy of prediction. The validation study confirmed the prognostic value of the admission NLR.

Conclusions: In orthogeriatric patients, high NLR on admission is an independent indicator of fracture presence, a significant risk factor and moderate predictor of postoperative myocardial injury, high inflammatory response/infection and in-hospital death.
\end{abstract}

Key words: neutrophil to lymphocyte ratio (NLR), orthogeriatric patients, hip fracture, outcomes

\section{Introduction}

With population ageing associated with high prevalence of osteoporosis, musculoskeletal, nervous system and cardiovascular diseases, high incidence of falls and fractures, the proportion of orthopaedic patients is rising. Preoperative multimorbidity of older adults $(>50 \%$ have three or more chronic diseases [1]) causes a significant increase in the burden of morbidity and mortality and requires 
specific management. Postoperative adverse outcomes dominated by cardiovascular events [2-6] and inflammatory complications [7-10] are associated with increased hospital stay, institutionalization, poorer quality of life, higher inpatient and long-term mortality, greater use of healthcare resources and substantially increased costs [11-13]. Although post-admission and postoperative conditions and complications contribute significantly to outcomes, it is important to identify preoperative outcomeaffecting risk factors related to both medical comorbidities and orthopaedic conditions and treatment. These, if modifiable, have the potential to improve the perioperative management and decrease postoperative morbidity and mortality. Unfortunately, there are no widely accepted, effective, clinically applicable predictors of outcomes to guide preventive and treatment choice in orthogeriatric patients.

Several studies which investigated the impact of different preoperative clinical factors, various scoring systems and admission blood tests [6, 14-25] on prediction of mortality risk following hip fracture (HF) surgery produced controversial results. Little is known about the usefulness of these markers and tools for prediction of other outcomes after HF repair, and it remains uncertain whether routinely available preoperative clinical and laboratory markers identify non-HF orthogeriatric patients at higher risk of major perioperative complications.

Over the past decade data have emerged that a high preoperative neutrophil to lymphocyte ratio (NLR), a systemic inflammatory-immunological marker, is an independent predictor of mortality in critically ill intensive care patients [26], after emergency abdominal surgery in the elderly [27], after major cardiac and vascular surgery [28] and after surgery for a variety of cancers [29-31]. NLR was also found to be a significant independent predictor of adverse outcomes in patients with coronary artery disease (CAD) [32-39], hypertension, ischaemic stroke [40], chronic kidney disease (CKD), diabetes mellitus $(\mathrm{DM})$, chronic heart failure (CHF), peripheral arterial disease $[33,35,37,38,41]$, and for survival in various cancer populations $[31,42,43]$, conditions common in the elderly. However, some studies failed to demonstrate its prognostic value, for example, in postoperative atrial fibrillation $\mathrm{AF}$ [44] and in different cancer types [45-47]. Patients with complications after major abdominal surgery did not present a higher preoperative NLR than those without [48], but an increased NLR on the first postoperative day indicated a greater risk of complications after colorectal surgery [49]. Because different cut-offs of NLR (ranging between 2.10 and 22.85) were used, the magnitude of the prognostic impact of NLR is still unclear, and controversy exist even in regard to different cancer types.

In orthopaedic patients, in contrast to that in other patient groups, this marker has been studied very little. In one study of HF patients, the preoperative NLR was not predictive of postoperative mortality, after surgery NLR decreased but NLR $>5$ at the $5^{\text {th }}$ postoperative day was associated with higher risk of postoperative mortality, cardiovascular complications and infections [50].

In the present study we aimed to investigate in orthogeriatric patients (1) the association of NLR on admission with presence of fracture and comorbid conditions known to affect outcomes, (2) to evaluate the prognostic value of NLR against established risk factors, and (3) to determine whether combined use of the NLR and other biomarkers on admission improves the prediction of short-term outcomes.

\section{Patients and Methods}

In total, 415 consecutive patients aged 60 years and over, who were admitted between 1 January 2010 and 31 August 2011 to the Department of Orthopaedic Surgery at the Canberra hospital (a 500-bed university-affiliated tertiary care centre), underwent surgery and for whom full clinical and laboratory data was available, were included in the study. The mean age of the cohort was $78.8 \pm 8.7$ years, 281 $(67.7 \%)$ were female, and 394 (95\%) were Caucasian. Of 415 patients $255(61.4 \%)$ had a non-vertebral bone fracture, including $167(40.2 \%)$ a HF. Among 160 non-fracture patients there were 143 subjects admitted for elective surgery, 6 patients with suspected surgical site infections (not confirmed by further investigation) and 11 patients with a prosthetic joint infection following total hip (8) or knee (3) arthroplasty. Data was collected prospectively on demographics, medical and orthopaedic diagnoses, laboratory characteristics, procedures performed, medication used, and short-term outcomes.

\section{Validation Dataset}

A retrospective analysis of a second cohort included data (obtained from electronic medical and administrative records) from 294 consecutive older ( $\geq 60$ years of age) patients (mean age $82.1 \pm 8.0$ years, $72.1 \%$ women) with osteoporotic HF who were treated at the Canberra Hospital between 2005 and 2007. Among all orthogeriatric patients this group is known to contribute the greatest to postoperative morbidity and mortality.

The study was conducted according to the standards of the Declaration of Helsinki and was approved by the local Health Human Research Ethical 
Committee. As only routinely collected patient data (anonymized before analysis) were used and none of the patients had a blood test for the purposes of the study itself, the need for informed consent was waived.

\section{Laboratory measurements}

In each patient venous blood samples were collected on admission and the following tests performed: complete blood count, electrolytes, renal (creatinine, urea), liver (ALT, GGT, ALP, albumin and total bilirubin) and thyroid function tests (thyroid stimulating hormone, TSH; thyroxine,T4), C-reactive protein (CRP), cardiac troponin I (cTnI), fasting blood glucose (and $\mathrm{HbA1C}$ in diabetic patients), $25(\mathrm{OH})$ vitamin D [25(OH)D], intact PTH, total calcium, phosphate and magnesium. All biochemical parameters were measured by standard automated laboratory methods and using commercially available kits according to the manufacturers' protocols. Serum cTnI was determined by a 2-step chemiluminescent microparticle immunoassay (Chemiflex, Abbott Labs, Mississauga, Ontario, Canada), 25(OH)D by a radioimmunoassay kit (Dia Sorin, Stillwater, $\mathrm{MN}$, USA), intact PTH by 2-site chemiluminescent enzymelinked immunoassay on DPC Immulite 2000 (Diagnostic Products, Los Angeles, CA). According to the manufacturer, the low detection limit for cTnI assay is $0.03 \mu \mathrm{g} / \mathrm{L}$ and the upper limit of reference range is $0.06 \mu \mathrm{g} / \mathrm{L}$. In this study all values of cTnI above this level were considered elevated, indicating myocardial injury. Glomerular filtration rate (GFR) was estimated by a standardized serum creatinine-based formula normalized to a body surface area of $1.73 \mathrm{~m}^{2}[51,52]$. Chronic kidney disease (CKD) was defined as a glomerular filtration rate (GFR) $<60 \mathrm{~mL} / \mathrm{min} / 1.73 \mathrm{~m}^{2}$, which represents a loss of half or more of the normal adult renal function level [53].

For the analyses, deficiency of vitamin $\mathrm{D}$ was defined as $25(\mathrm{OH}) \mathrm{D}<25 \mathrm{nmol} / \mathrm{L}$ and insufficiency as $25(\mathrm{OH}) \mathrm{D}<50 \mathrm{nmol} / \mathrm{L}$ based on current recommendations. Secondary hyperparathyroidism (SHPT) was defined as elevated serum PTH $(>6.8$ $\mathrm{pmol} / \mathrm{L}$, the upper limit of the laboratory reference range). Cut-off values for neutrophil count $\left(>8.0 \times 10^{9} / \mathrm{L}\right)$, lymphocyte count $\left(<1.2 \times 10^{9}\right)$ and serum albumin level $(<33 \mathrm{~g} / \mathrm{L})$ were defined as greater than the upper limit or lower than the low limit of normal range, respectively.

\section{Short-term outcomes}

These included: (1) in-hospital all-cause mortality, (2) postoperative myocardial injury defined by cardiac cTnI I rise (cTnI $>0.06 \mu \mathrm{g} / \mathrm{L})$, a marker unique to myocardium, (3) high inflammatory response $\left(\mathrm{CRP}>100 \mathrm{mg} / \mathrm{L}\right.$ or $>150 \mathrm{mg} / \mathrm{L}$ after the $3^{\text {rd }}$ postoperative day), (4) prolonged length of stay $(>10$ days) and (5) being discharged to a permanent residential care facility (RCF). According to our standard postoperative care protocol, in all patients aged $\geq 60$ years, CRP and cTnI measurements were performed on the first 3 days after surgery and thereafter if elevated. The postoperative cTnI rise was chosen as an important indicator of short-term outcome because myocardial injury/necrosis (diagnosed with an elevated cTnI measurement) is the most common cardiovascular complication after noncardiac surgery, asymptomatic in up to $80 \%$ of patients but known to be associated with significant in-hospital and long-term morbidity and mortality [5, 54-57].

Elevated CRP, a widely recognised parameter for early detection of postoperative infections, reflects also the extent of surgical trauma. The hepatic synthesis of CRP due to bacterial infection is known to start 6-8 hours after infection, reached its peak on the second-third postoperative day (36 - 50 hours) [58-61], a level of $\geq 96 \mathrm{mg} / \mathrm{L}$ after the fourth day of surgery is highly indicative for deep wound infection [62]. Importantly, the CRP response after orthopaedic surgery is more informative than white blood cell count (WBC) [59, 63], absolute neutrophil count and erythrocyte sedimentation rate [58, 64], and is not associated with age, gender, type of anaesthesia, operation time, amount of bleeding, transfusion or drugs administered [58]. On these bases persistent elevation and/or second rise in CRP concentrations $(\mathrm{CRP}>100 \mathrm{mg} / \mathrm{L}$ and CRP $>150 \mathrm{mg} / \mathrm{L})$ after the $3^{\text {rd }}$ postoperative day were chosen as indicators of possible postoperative infective complications.

\section{Statistical analyses}

Continuous variables are reported as means \pm standard deviation (SD) and compared using the Student's $t$ test. Categorical variables are presented as proportions/percentages and compared by Chi-square and Fisher exact tests. The admission NLR was analysed as both a continuous and a categorical variable; in the latter, NLR was categorized into 3 groups (stratified by tertiles). The associations between NLR and presence of any fracture, HF and outcomes were estimated with univariate and multivariate linear logistic regression models and reported as odds ratios (OR) with 95\% confidence interval (CI); all potential confounding variables (demographic, clinical and laboratory) with statistical significance $\leq 0.15$ on univariate analyses were included in multivariate models to identify independent factors associated with fractures and/or poorer short-term outcomes. In the univariate 
analysis, age was explored both by category and as a continuous variable. In the multivariate analysis, age was treated as a continuous variable. We compared the predictive values of NLR in the $2^{\text {nd }}$ and $3^{\text {rd }}$ tertiles with that in the $1^{\text {st }}$. To quantify the potential predictive utility for NLR and other parameters of interest receiver operating characteristic (ROC) analysis was used and the predictive accuracy was expressed as area under curve (AUC). To quantify the significance of multicollinearity phenomena in regression analyses the variance inflation factor was calculated. Two-tailed p-values $<0.05$ were considered statistically significant. The Stata software version 10 (StataCorp, College Station, TX, USA) was used for all statistical analyses.

\section{Results}

\section{Patient characteristics}

The main clinical and laboratory characteristics of the study population are displayed in Table 1. At least one cardiovascular disease (CVD) was present in $315(75.9 \%)$ patients. Anaemia (haemoglobin $<120 \mathrm{~g} / \mathrm{L}$ ) was diagnosed in 330 (79.5\%) patients, CKD in 79 $(19.0 \%)$, type 2 diabetes mellitus (DM) in $80(19.3 \%)$, dementia in 73 (17.6\%), vitamin D insufficiency in 148 $(35.7 \%)$ and hyperparathyroidism in 164 (39.5\%) subjects.

\section{Relationships between the NLR and clinical characteristics}

On admission the mean white cells, neutrophil and lymphocyte counts were $8.91 \pm 3.67 \times 10^{9} / \mathrm{L}, 7.61 \pm$ $2.47 \times 10^{9} / \mathrm{L}$ and $1.27 \pm 1.18 \times 10^{9} / \mathrm{L}$, respectively; the mean NLR was $8.24 \pm 6.58$. The mean NLRs were significantly higher in patients $>75$ years of age, with any fracture, $\mathrm{HF}$, dementia, $\mathrm{AF}, \mathrm{CHF}, \mathrm{CKD}$, anaemia, hypoalbuminaemia, vitamin $\mathrm{D}$ deficiency and elevated PTH level; in patients with CAD the difference was of borderline significance $(p=0.052)$, while patients with OA demonstrated lower mean NLR compared to the rest of the cohort (Table 1). In contrast, the mean NLRs did not differ by gender, presence of hypertension, cerebrovascular disease, peripheral vascular disease, DM, Parkinson's disease, COPD, history of cancer, smoking (current or past), alcohol consumption and use of walking aids. Preoperative NLR evaluated as a continuous variable revealed that each 1-unit increase in NLR was associated with increased probability of being $>75$ years of age by $9.3 \%$, of having any fracture by $7.8 \%$, a HF by $12.3 \%$, dementia by $6.4 \%$, AF by $3.4 \%$, CHF by $4.9 \%$, CKD by $6.1 \%$, vitamin D deficiency by $4.2 \%$, hyperparathyroidism by $4.9 \%$, of being anaemic by $10.3 \%$, and hypoalbuminaemic by $15.2 \%$ (Table 1 ).

Table 1. Clinical characteristics and admission neutrophil to lymphocyte ratio (NLR) in orthogeriatric patients $(n=415)$

\begin{tabular}{|c|c|c|c|c|c|c|}
\hline Characteristics & Sign present & Sign absent & P value & OR & 95\%CI & P value \\
\hline Age $>75$ yr $(n=277,66.7 \%)$ & $9.09 \pm 7.23$ & $6.54 \pm 4.62$ & 0.0002 & 1.093 & $1.042-1.146$ & 0.000 \\
\hline Gender (females, $\mathrm{n}=281,67.7 \%$ ) & $8.06 \pm 6.18$ & $8.62 \pm 7.34$ & 0.4195 & 1.012 & $0.982-1.044$ & 0.421 \\
\hline Any fracture $(\mathrm{n}=255,61.4 \%)$ & $9.17 \pm 7.45$ & $6.79 \pm 4.55$ & 0.0003 & 1.078 & $1.033-1.125$ & 0.001 \\
\hline Hip fracture $(n=167,40.2 \%)$ & $10.57 \pm 8.42$ & $6.69 \pm 4.34$ & 0.0000 & 1.123 & $1.076-1.172$ & 0.000 \\
\hline Hypertension $(n=260,62.7 \%)$ & $8.53 \pm 7.05$ & $7.75 \pm 5.71$ & 0.2434 & 1.019 & $0.987-1.053$ & 0.246 \\
\hline CAD $(n=74,17.8 \%)$ & $9.59 \pm 8.77$ & $7.95 \pm 5.98$ & 0.0517 & 1.032 & $0.999-1.067$ & 0.060 \\
\hline MI $(n=33,8.0 \%)$ & $9.52 \pm 6.91$ & $8.13 \pm 6.55$ & 0.2453 & 1.023 & $0.982-1.072$ & 0.251 \\
\hline CVA $(n=28,6.7 \%)$ & $10.18 \pm 9.37$ & $8.10 \pm 6.33$ & 0.1074 & 1.035 & $0.991-1.081$ & 0.117 \\
\hline TIA $(n=22,5.3 \%)$ & $7.66 \pm 4.48$ & $8.37 \pm 6.68$ & 0.6688 & 0.984 & $0.912-1.060$ & 0.668 \\
\hline $\mathrm{AF}(\mathrm{n}=71,17.1 \%)$ & $9.71 \pm 7.23$ & $7.94 \pm 6.41$ & 0.0393 & 1.034 & $1.000-1.070$ & 0.047 \\
\hline $\mathrm{CHF}(\mathrm{n}=44,10.6 \%)$ & $10.85 \pm 8.95$ & $7.93 \pm 6.19$ & 0.0053 & 1.049 & $1.011-1.088$ & 0.010 \\
\hline PVD $(n=20,4.9 \%)$ & $8.59 \pm 5.37$ & $8.22 \pm 6.64$ & 0.8105 & 1.008 & $0.946-1.074$ & 0.810 \\
\hline $\mathrm{DM}(\mathrm{n}=80,19.3 \%)$ & $8.01 \pm 6.78$ & $8.30 \pm 6.54$ & 0.7253 & 0.993 & $0.955-1.032$ & 0.725 \\
\hline Dementia $(n=73,17.6 \%)$ & $11.0 \pm 9.66$ & $7.65 \pm 5.56$ & 0.0001 & 1.064 & $1.028-1.101$ & 0.000 \\
\hline Parkinson's disease $(n=15,3.6 \%)$ & $10.20 \pm 7.40$ & $8.17 \pm 6.55$ & 0.2403 & 1.034 & $0.977-1.093$ & 0.248 \\
\hline Cancer $(n=84,20.2 \%)$ & $9.29 \pm 6.37$ & $7.97 \pm 6.62$ & 0.1009 & 1.027 & $0.994-1.061$ & 0.108 \\
\hline OA $(n=194,46.7 \%)$ & $7.32 \pm 4.78$ & $9.05 \pm 7.75$ & 0.0074 & 0.955 & $0.923-0.99$ & 0.010 \\
\hline Any CVD ( $\mathrm{n}=315,75.9 \%)$ & $8.32 \pm 6.76$ & $7.98 \pm 6.00$ & 0.6503 & 1.001 & $0.973-1.045$ & 0.650 \\
\hline $\operatorname{COPD}(\mathrm{n}=46,11.1 \%)$ & $8.06 \pm 6.55$ & $8.26 \pm 6.59$ & 0.8452 & 0.995 & $0.948-1.045$ & 0.845 \\
\hline Smoker $(\mathrm{n}=36,8.7 \%)$ & $7.65 \pm 5.72$ & $8.30 \pm 6.66$ & 0.5714 & 0.983 & $0.926-1.043$ & 0.571 \\
\hline Ex-smoker $(n=83,20.0 \%)$ & $8.03 \pm 5.13$ & $8.30 \pm 6.90$ & 0.7394 & 0.994 & $0.956-1.032$ & 0.739 \\
\hline Alcohol over-user n=79, 19.0\%) & $7.46 \pm 4.62$ & $8.43 \pm 6.96$ & 0.2422 & 0.974 & $0.932-1.018$ & 0.244 \\
\hline Walking aids user $(n=168,40.5 \%)$ & $8.28 \pm 5.21$ & $8.22 \pm 7.38$ & 0.9289 & 1.001 & $0.972-1.031$ & 0.929 \\
\hline $\mathrm{CKD}(\mathrm{n}=79,19.0 \%)$ & $10.74 \pm 10.03$ & $7.65 \pm 5.32$ & 0.0002 & 1.061 & $1.025-1.097$ & 0.001 \\
\hline Albumin<33g/L ( $\mathrm{n}=167,40.4 \%)$ & $10.86 \pm 8.46$ & $6.48 \pm 4.10$ & 0.0000 & 1.152 & $1.100-1.207$ & 0.000 \\
\hline Haemoglobin $<120 \mathrm{~g} / \mathrm{L}(\mathrm{N}=330,79.5 \%)$ & $8.75 \pm 6.87$ & $6.25 \pm 4.89$ & 0.0017 & 1.103 & $1.038-1.173$ & 0.002 \\
\hline $25(\mathrm{OH}) \mathrm{D}<25 \mathrm{nmol} / \mathrm{L}(\mathrm{n}=39,9.4 \%)$ & $10.47 \pm 7.77$ & $8.00 \pm 6.43$ & 0.0258 & 1.042 & $1.003-1.082$ & 0.034 \\
\hline $25(\mathrm{OH}) \mathrm{D}<50 \mathrm{nmol} / \mathrm{L}(\mathrm{n}=148,35.7 \%)$ & $8.92 \pm 8.23$ & $7.86 \pm 5.45$ & 0.1165 & 1.024 & $0.993-1.055$ & 0.123 \\
\hline PTH $>6.8 \mathrm{pmol} / \mathrm{L}(\mathrm{n}=164,39.5 \%)$ & $9.46 \pm 7.43$ & $7.44 \pm 5.85$ & 0.0022 & 1.049 & $1.016-1.084$ & 0.004 \\
\hline
\end{tabular}

Data are mean values $( \pm \mathrm{SD})$ and univariate logistic regression.

Abbreviations: $\mathrm{OR}$, odds ratio; $\mathrm{CI}$, confidence interval; $\mathrm{CAD}$, coronary artery disease; $\mathrm{MI}$, myocardial infarction; CVA, cerebrovascular accident; $\mathrm{TIA}$, transient ischaemic attack; $\mathrm{AF}$, atrial fibrillation; $\mathrm{CHF}$, chronic heart failure; $\mathrm{PVD}$, peripheral vascular disease; $\mathrm{CVD}$, cardiovascular disease; $\mathrm{DM}$, diabetes mellitus; $\mathrm{COPD}$, chronic obstructive pulmonary disease; CKD, chronic kidney disease (estimated glomerular filtration rate, eGFR<60ml/min/1.73 $\mathrm{m}^{2}$ ); OA, osteoarthritis; 25(OH)D, 25-hydroxyvitamin D; PTH, parathyroid hormone. 
We then investigated in multivariate models the associations between NLR as a continuous variable and presence of fracture including all parameters shown to be linked to NLR in univariate analyses $(p \leq 0.150)$ and controlling for age and sex. These demonstrated that preoperative NLR remained an independent indicator of a HF (OR 1.060, 95\% CI 1.010-1.118, $\mathrm{p}=0.030$ ) but not of any fracture (OR 1.036, 95\% CI 0.988-1.086, $\mathrm{p}=0.141)$. On the other hand, in a similar multivariate regression model with NLR as a continuous dependent variable dementia $(\beta=2.038$, $95 \%$ CI $0.084-3.99, \mathrm{p}=0.041)$ was the positive and albumin $(\beta=-0.357,95 \% \mathrm{CI}-0.534--0.180, \mathrm{p}=0.000)$ and eGFR levels $(\beta=-0.032,95 \% \mathrm{CI}-0.062--0.001$, $\mathrm{p}=0.042$ ) were the negative independent determinants of higher NLR, while presence of HF was only of borderline significance $(\beta=1.625,95 \% \mathrm{CI}-0.069-3.319$, $\mathrm{p}=0.060)$. In other words, higher NLR is an independent consistent indicator of presence of $\mathrm{HF}$, but the opposite is not always true.

When dividing the patients according to tertiles of NLR, subjects in the highest tertile $(>8.5$, mean $\pm S D: 14.69 \pm 7.91)$ compared to subjects in the first tertile $(<5.1$, mean \pm SD:3.42 \pm 1.06$)$ were significantly older $(80.8 \pm 8.5$ vs.76.8 \pm 8.6 years, $p=0.0005)$, more likely to have any fracture $(72.1 \%$ vs. $49.3 \%, p=0.000)$

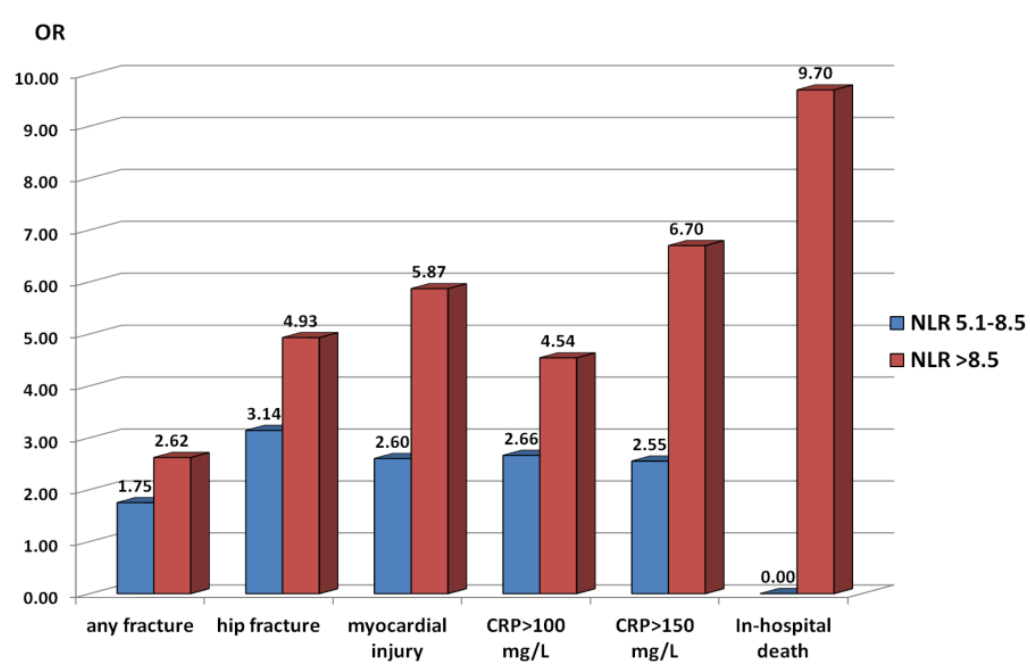

Figure 1. Odds ratios (OR) for presence of fracture and specific short-term outcomes in orthogeriatric patients according to neutrophil to lymphocyte ratio (NLR) tertiles on admission. Patients with admission NLR in the second $(5.1-8.5)$ and third $(>8.5)$ tertiles are compared to those with NLR $<5.1$ (first tertile) for all shown outcomes except in-hospital death. The OR for in-hospital death reflects the comparison of patients with admission NLR>8.5 and those with NLR 5.1 - 8.5 (no fatal outcomes were observed among patients with NLR<5.1 on admission). Abbreviations: CRP, C-reactive protein; myocardial injury, postoperative cardiac troponin I rise. or a $\operatorname{HF}(55.1 \%$ vs. $20.0 \%, \mathrm{p}=0.000), \operatorname{AF}(23.5 \%$ vs. 13.6 $\%, \mathrm{p}=0.033)$, dementia $(22.1 \%$ vs.11.4\%, $\mathrm{p}=0.018)$, history of cancer $(27.9 \%$ vs.15.0\%, $\mathrm{p}=0.009)$, anaemia $(88.2 \%$ vs. $68.6 \%, p=0.000)$, and hyperparathyroidism $(48.9 \%$ vs. $28.1 \%, \mathrm{p}=0.001)$, as well as lower serum albumin ( $32.1 \pm 4.7$ vs. $35.7 \pm 4.2 \mathrm{~g} / \mathrm{L}, \mathrm{p}=0.0001)$ levels, erythrocyte $\left(3.31 \pm 0.57\right.$ vs. $\left.3.62 \pm 0.53 \times 10^{12} / \mathrm{L}, \mathrm{p}=0.0001\right)$ and lymphocyte counts $\left(0.72 \pm 0.25\right.$ vs. $1.94 \pm 1.80 \times 10^{9} / \mathrm{L}$, $\mathrm{p}=0.0001)$, and higher total leukocyte count $\left(10.30 \pm 3.99\right.$ vs. $\left.7.75 \pm 4.05 \times 10^{9} / \mathrm{L}, \quad \mathrm{p}=0.0001\right)$ and creatinine concentrations $\quad(89.4 \pm 72.4 \quad$ vs.74.6 \pm 27.7 $\mu \mathrm{mol} / \mathrm{L}, \mathrm{p}=0.0249$ ).

In multivariate logistic regression models which included all clinical and laboratory factors associated with higher NLR with a value of $p \leq 0.15$ in univariate analyses after adjusting for age and sex, the independent determinants of preoperative NLR $\geq 5.1$ were presence of HF (OR 2.66, 95\% CI 1.38 - 5.12, $\mathrm{p}=0.003$ ), lower levels of albumin (OR 0.92, 95\%CI $0.86-0.99, \mathrm{p}=0.019$ ) and haemoglobin (OR 0.98, $95 \% \mathrm{CI} 0.96-0.99, \mathrm{p}=0.028)$ and higher serum $\mathrm{PTH}$ concentration (OR 1.09, 95\% CI $1.01-1.19, \mathrm{p}=0.036$ ); presence of any fracture was of borderline significance (OR 1.61, 95\% CI $0.95-2.71, \mathrm{p}=0.077$ ).

In comparison to subjects with preoperative NLR levels $<5.1$ (first tertile, referent category), patients with $\mathrm{NLR} \geq 5.1$ were about 2 times more likely to present with a fracture (OR $2.12,95 \% \mathrm{CI} 1.40-3.22, \mathrm{p}=0.000)$ and 3.9 times more likely to have a HF (OR 3.90, $95 \%$ CI $2.34-6.52, p=0.000)$. Patients with NLR in the range of 5.1 - 8.5 (intermediate tertile) were 1.75 -fold more likely to have any fracture (OR 1.75, 95\% CI1.08-2.91, $\mathrm{p}=0.022$ ) and 3.14-fold more likely to have a HF (OR 3.14, 95\%CI 1.70- 5.80, $\mathrm{p}=0.000$ ), whereas patients with NLR in the category of $>8.5$ (high tertile) were 2.62-fold more likely to have any fracture (OR 2.62, 95\% CI 1.54-4.46, $\mathrm{p}=0.000$ ) and 4.93-fold more likely to have a HF (OR 4.93, 95\%CI 2.64 9.28, $\mathrm{p}=0.000$ ) (Figure 1).

\section{Admission NLR and short-term outcomes}

Postoperative complications and outcomes are shown in Table 2 . Postoperative myocardial injury with cTnI rise was caused by acute pulmonary oedema due to fluid overload, myocardial ischaemia associated with anaemia and sepsis, acute coronary syndrome and pulmonary embolism; it was observed in $75(18.1 \%)$ patients. A significant 
inflammatory response which persisted 3 days after surgery with CRP>100 mg/L was seen in 200 (48.2\%) patients and with CRP>150 mg/L in 129 (31.1\%) patients; it was related mainly to urinary tract, pulmonary, skin or wound infections. Prolonged hospital stay (LOS>10 days) occurred in 211 (50.8\%) patients. Overall postoperative in-hospital mortality rate was $2.4 \%$; 9 of 10 patients who died presented with a HF (the mortality rate for HF was $6.0 \%$ ). Of 322 patients admitted from home 22 were discharged to permanent RCF.

Patients with all above mentioned postoperative outcomes, except being discharged to RCF, had significantly higher mean NLRs on admission (Table 2) and in univariate analysis NLR was significantly associated with these short-term outcomes. With each unit increase in preoperative NLR there was a $13.6 \%$, $12.5 \%, 4.3 \%$ and $9.7 \%$ increase in postoperative myocardial injury, inflammatory complications, prolonged hospital stay and in-hospital death, respectively. Admission NLR did not influence the incidence of discharges to RCF among subjects admitted from home (OR 1.26, 95\% 0.93- 1.71, $\mathrm{p}=0.141$ ).

We then investigated in multivariate models the associations between NLR as a continuous variable and outcomes (as dependent variables) including presence of $\mathrm{CAD}, \mathrm{AF}, \mathrm{CHF}$, cerebrovascular disease, dementia, cancer, osteoarthritis, any fracture or HF, eGFR, haemoglobin, 25(OH)D and PTH levels, age and gender as independent variables. These demonstrated that preoperative NLR remained an independent predictor of postoperative death, myocardial injury and inflammatory complications. For every unit increase in the NLR, there was a $10.6 \%$ increased risk of in-hospital death, a $8.6 \%$ increased risk of cTnI rise, a $8.1 \%$ higher risk of developing an inflammatory response with $\mathrm{CRP}>100 \mathrm{mg} / \mathrm{L}$ and a 9.4\% higher risk of having CRP>150 mg/L. NLR, however, was not an independent predictor of prolonged LOS in multivariate analysis.

Among other laboratory variables hypoalbuminaemia preoperatively appeared as the most informative predictor of outcomes. Every 1-unit decrease in serum albumin was associated with a $15.5 \%$ higher risk of postoperative cTnI rise (OR 0.845, $95 \%$ CI $0.775-0.922, p=0.000)$, a $8.5 \%$ higher risk of having CRP $>100 \mathrm{mg} / \mathrm{L}$ (OR 0.915, 95\%CI 0.861-0.972, $\mathrm{p}=0.004$ ), a $7.0 \%$ higher risk of CRP $>150 \mathrm{mg} / \mathrm{L}$ (OR $0.930,95 \%$ CI $0.873-0.990, \mathrm{p}=0.023$ ) and a $6.4 \%$ higher risk of hospital stay $>10$ days (OR 0.936, 95\%CI 0.886-0.989, $\mathrm{p}=0.018$ ). Higher serum PTH levels were independently associated with mortality (OR1.171, 95\% CI 1.035-1.323, $\mathrm{p}=0.012$ ). Lower admission haemoglobin levels were independently predictive for postoperative inflammation with $\mathrm{CRP}>100 \mathrm{mg} / \mathrm{L}$ (OR 0.964, 95\%CI 0.948-0.980, $\mathrm{p}=0.000)$ and $\mathrm{CRP}>150$ $\mathrm{mg} / \mathrm{L}$ (OR 0.979, 95\% CI 0.963-0.996, $\mathrm{p}=0.014$ ).

Patients with NLR at admission in the range of 5.1 - 8.5 (intermediate tertile) compared to patients with NLR levels <5.1, postoperatively had a 2.6 times higher risk of myocardial injury (OR 2.60, 95\% CI 1.12 - 6.14, $\mathrm{p}=0.014)$ and/or inflammatory complications (for CRP>100mg/L: OR 2.66, 95\%CI 1.57 - 4.51, $\mathrm{p}=0.000$; for $\mathrm{CRP}>150 \mathrm{mg} / \mathrm{L}$ : OR $2.55,95 \% \mathrm{CI} 1.34-$ 4.91, $\mathrm{p}=0.002)$, whereas patients with preoperative NLR>8.5 (high tertile) had a 5.87- (OR 5.87, 95\%CI 2.67 - 13.20, $\mathrm{p}=0.000$ ), 4.54 - 6.70-fold (for CRP>100mg/L: OR 4.54, 95\%CI $2.65-7.81, \mathrm{p}=0.000$; for $\mathrm{CRP}>150 \mathrm{mg} / \mathrm{L}$ : OR $6.70,95 \% \mathrm{CI} 3.58$ - 12.64, $\mathrm{p}=0.000$ ) higher risk of myocardial injury and inflammatory complications, respectively, indicating a dose-response relationship (Figure 1). None of the 10 patients who died had a preoperative NLR $<5.1$, and in 9 subjects it was above 8.5 , suggesting that the risk of a fatal outcome in subjects with NLR>8.5 on admission was near 10 times higher in comparison with patients whose NLR was in the range of 5.1 - 8.5 (OR 9.71, 95\% CI $1.24-207.53, \mathrm{P}=0.009$ ).

Table 2. Admission neutrophil to lymphocyte ratio (NLR) and postoperative outcomes in orthogeriatric patients

\begin{tabular}{|c|c|c|c|c|c|c|}
\hline Outcome & $\begin{array}{l}\text { Outcome } \\
\text { present }\end{array}$ & $\begin{array}{l}\text { Outcome } \\
\text { absent }\end{array}$ & P value & OR & $95 \% \mathrm{CI}$ & P value \\
\hline In-hospital death $(n=10,2.4 \%)$ & $18.35 \pm 7.88$ & $8.00 \pm 6.37$ & 0.0000 & $\begin{array}{l}1.097 \\
1.106\end{array}$ & $\begin{array}{l}1.044-1.152 \\
1.002-1.221\end{array}$ & $\begin{array}{l}0.000 \\
0.045\end{array}$ \\
\hline$C R P>100 \mathrm{mg} / \mathrm{L}(\mathrm{n}=200,48.2 \%)$ & $10.11 \pm 7.88$ & $6.52 \pm 4.45$ & 0.0000 & $\begin{array}{l}1.126 \\
1.081\end{array}$ & $\begin{array}{l}1.076-1.177 \\
1.030-1.134\end{array}$ & $\begin{array}{l}0.000 \\
0.002\end{array}$ \\
\hline $\mathrm{CRP}>150 \mathrm{mg} / \mathrm{L}(\mathrm{n}=129,31.1 \%)$ & $11.29 \pm 8.41$ & $6.88 \pm 5.01$ & 0.0000 & $\begin{array}{l}1.124 \\
1.094\end{array}$ & $\begin{array}{l}1.078-1.171 \\
1.045-1.146\end{array}$ & $\begin{array}{l}0.000 \\
0.000\end{array}$ \\
\hline Troponin rise $(n=75,18.1 \%)$ & $13.18 \pm 10.68$ & $7.12 \pm 4.60$ & 0.0000 & $\begin{array}{l}1.136 \\
1.086\end{array}$ & $\begin{array}{l}1.088-1.185 \\
1.032-1.142\end{array}$ & $\begin{array}{l}0.000 \\
0.001\end{array}$ \\
\hline LOS $>10$ days $(n=211,50.8 \%)$ & $9.05 \pm 7.41$ & $7.40 \pm 5.49$ & 0.0106 & $\begin{array}{l}1.043 \\
1.019\end{array}$ & $\begin{array}{l}1.009-1.079 \\
0.982-1.058\end{array}$ & $\begin{array}{l}0.014 \\
0.310\end{array}$ \\
\hline
\end{tabular}

Data are mean values $( \pm \mathrm{SD})$, univariate (first line) and multivariate (second line) logistic regression analyses.

Adjustments: age, sex, presence of any fractures or HF, history of coronary artery disease, hypertension, cerebrovascular disease, atrial fibrillation, chronic heart failure, peripheral vascular disease, diabetes mellitus, cancer, dementia, chronic obstructive airway disease, chronic kidney disease $\left(\mathrm{eGFR}<60 \mathrm{ml} / \mathrm{min} / 1.73 \mathrm{~m}^{2}\right)$, haemoglobin $<120 \mathrm{~g} / \mathrm{L}$, albumin $<33 \mathrm{~g} / \mathrm{L}, 25(\mathrm{OH}) \mathrm{D}<25 \mathrm{nmol} / \mathrm{L}, \mathrm{PTH}>6.8 \mathrm{pmol} / \mathrm{L}$, smoking status and alcohol overuse ( $\geq 3$ drinks/week).

Abbreviations: OR, odds ratio; CI, confidence interval; CRP, C-reactive protein; LOS, length of hospital stay. 
Table 3. Characteristics on admission independently associated with presence of any fracture, hip fracture and postoperative myocardial injury and extended inflammatory response in orthogeriatric patients (multivariate logistic regression analyses)

\begin{tabular}{|c|c|c|c|c|c|c|c|c|c|c|}
\hline \multirow[b]{2}{*}{ Characteristic } & \multicolumn{2}{|l|}{ Any fracture } & \multicolumn{2}{|l|}{ Hip fracture } & \multicolumn{2}{|l|}{ Troponin rise } & \multicolumn{2}{|l|}{$C R P>100 \mathrm{mg} / \mathrm{L}$} & \multicolumn{2}{|l|}{$\mathrm{CRP}>150 \mathrm{mg} / \mathrm{L}$} \\
\hline & OR (95\%CI) & P value & OR (95\%CI) & P value & OR (95\%CI) & Pvalue & OR $(95 \% \mathrm{CI})$ & P value & OR $(95 \% C I)$ & P value \\
\hline NLR $>5.1$ & $1.74(1.08 ; 2.79)$ & 0.023 & $3.11(1.69 ; 5.74)$ & 0.000 & $2.40(1.11 ; 5.22)$ & 0.026 & $2.42(1.48 ; 3.95)$ & 0.000 & $3.17(1.75 ; 5.74)$ & 0.000 \\
\hline Age & $1.07(1.03 ; 1.10)$ & 0.000 & $1.10(1.06 ; 1.15)$ & 0.000 & $1.05(1.01 ; 1.10)$ & 0.011 & & & & \\
\hline $\operatorname{Sex}(M)$ & & & & & $2.32(1.21 ; 4.42)$ & 0.011 & $1.93(1.17 ; 3.18)$ & 0.010 & & \\
\hline Dementia & $2.50(1.20 ; 5.25)$ & 0.015 & $3.58(1.58 ; 8.08)$ & 0.002 & & & & & & \\
\hline $\mathrm{AF}$ & & & & & $2.29(1.08 ; 4.85)$ & 0.030 & & & & \\
\hline Albumin $<33 \mathrm{~g} / \mathrm{L}$ & $2.09(1.27 ; 3.46)$ & 0.004 & $3.27(1.82 ; 5.87)$ & 0.000 & $4.21(2.16 ; 8.2)$ & 0.000 & $3.42(2.10 ; 5.56)$ & 0.000 & $2.72(1.63 ; 4.56)$ & 0.000 \\
\hline $\mathrm{Hb}<120 \mathrm{~g} / \mathrm{L}$ & & & & & & & $2.94(1.56 ; 5.58)$ & 0.001 & $2.53(1.14 ; 5.63)$ & 0.023 \\
\hline $\begin{array}{l}\mathrm{eGFR}<60 \\
\mathrm{ml} / \mathrm{min} / 1.73 \mathrm{~m}^{2}\end{array}$ & & & & & & & & & $2.28(1.25 ; 4.13)$ & 0.007 \\
\hline PTH>6.8 pmol/L & & & & & & & & & $1.92(1.16 ; 3.16)$ & 0.011 \\
\hline
\end{tabular}

Next, we assessed in multivariate models the independent characteristics associated with presence of any fracture, $\mathrm{HF}$, as well as adverse postoperative outcomes using the NLR as a categorical variable and adjusting for age, gender, history of CAD, hypertension, cerebrovascular disease, $\mathrm{AF}, \mathrm{CHF}$, PVD, DM, cancer, dementia, chronic COPD, CKD, haemoglobin $<120 \mathrm{~g} / \mathrm{L}$, albumin $<33 \mathrm{~g} / \mathrm{L}, 25(\mathrm{OH}) \mathrm{D}<25$ $\mathrm{nmol} / \mathrm{L}$, PTH $>6.8 \mathrm{pmol} / \mathrm{L}$, smoking status (current and former) and alcohol overuse ( $\geq 3$ drinks/week); the postoperative outcomes were adjusted also for presence of any fracture or HF (Table 3). Patients with admission NLR $\geq 5.1$ compared with those in the lowest tertile of NLR $(<5.1)$ had significantly greater odds of presenting with any fracture (OR 1.74) or HF (OR 3.11), and of experiencing postoperative myocardial injury (OR 2.40), inflammatory complications with $\mathrm{CRP}>100 \mathrm{mg} / \mathrm{L}$ (OR 2.42) or CRP>150 mg/L (OR 3.17). Hypoalbuminaemia $(<33 \mathrm{~g} / \mathrm{L})$ on admission was the only other independent indicator of fracture, HF and all these postoperative complications with ORs comparable to those of NLR. Dementia was strongly associated with fractures, especially HF. Presence of AF was an independent predictor of cTnI rise. Preoperative anaemia (haemoglobin $<120 \mathrm{~g} / \mathrm{L}$ ), CKD and elevated PTH were identified as independent risk factors for a high inflammatory response. The NLR $>8.5$ on admission (OR 16.63, 95\%CI 1.70 - 163.09, p=0.016), history of CHF (OR 7.52, 95\%1.00 -57.78, $\mathrm{p}=0.050$ ) and cancer (OR 6.35, 95\%CI1.13 - 32.09, p=0.025) were the only independent predictors of in-hospital death. Thus, NLR $\geq 5.1$ on admission after adjustment for variables known to predict poorer postoperative outcomes remained independently associated with presence of any fracture, HF and predictive of postoperative myocardial injury, inflammatory complications and in-hospital death.

The potential prognostic value of elevated NLR was evaluated by c-statistics on the basis of tertiles with cut-offs $\geq 5.1$ and $>8.5$. The NLR $\geq 5.1$ predicted postoperative myocardial injury with an area under the curve (AUC) of $0.738(\mathrm{p}=0.000), C R P>100 \mathrm{mg} / \mathrm{L}$ with AUC of $0.659(p=0.000), C R P>150 \mathrm{mg} / \mathrm{L}$ with AUC of $0.664(\mathrm{p}=0.000)$ and in-hospital mortality with an AUC of $0.763(\mathrm{p}=0.002)$; the NLR $>8.5$ predicted in-hospital mortality with an AUC of $0.847(\mathrm{p}=0.000)$. The NLR $\geq 5.1$ showed moderately high sensitivity for predicting postoperative myocardial injury $(86.7 \%)$, $\mathrm{CRP}>100 \mathrm{mg} / \mathrm{L} \quad(80 \%)$ and $\mathrm{CRP}>150 \mathrm{mg} / \mathrm{L} \quad(85.3 \%)$, low specificity (38.5\%, 46.3\%, 42.1\%, respectively) and low positive predictive value (PPV, $23.8 \%, 58.2 \%$ and $40.0 \%$ respectively), but a reasonable negative predictive value (NPV, 92.9\%, 71.2\% and 86.3\% respectively). NLR>8.5 for in-hospital mortality demonstrated high sensitivity (90\%) and NPV (99.6\%), but was considerably less specific (68.6\%). These data indicate that the prognostic value of elevated NLR, except NLR>8.5 for in-hospital mortality, is only modest (accuracy ranged between $69.1 \%$ and $47.2 \%$ ).

Further we compared the predictions of NLR with that of different other factors on admission, including: (1) neutrophils $>8.0 \times 10^{9} / \mathrm{L}$, (2) lymphocytes $<1.2 \times 10^{9} / \mathrm{L}$, (3) haemoglobin $<120 \mathrm{~g} / \mathrm{l}$, albumin $<33 \mathrm{~g} / \mathrm{L}, \quad$ (5) $\quad 25(\mathrm{OH}) \mathrm{D}<50 \mathrm{nmol} / \mathrm{L}$, $25(\mathrm{OH}) \mathrm{D}<25 \mathrm{nmol} / \mathrm{L}, \quad$ (7) $\mathrm{PTH}>6.8 \mathrm{pmol} / \mathrm{L}$, (8) eGFR $<60 \mathrm{ml} / \mathrm{min} / 1.73 \mathrm{~m}^{2}$, (9) age $>75$ years, (10) presence of CVD (any), (11) presence of AF and (12) dementia. Each of these factors, except albumin $<33 \mathrm{~g} / \mathrm{L}$, performed worse than NLR $\geq 5.1$ and yielded an AUC of 0.586 -0. 459 (for different outcomes). Comparing with NLR $\geq 5.1$, the haemoglobin $<120 \mathrm{~g} /$ had higher sensitivity but very low specificity for predicting myocardial injury $(89.5 \%$ and $22.8 \%$, respectively), as well as for CRP $>100 \mathrm{mg} / \mathrm{L}(91.0 \%$ and $30.8 \%$, respectively) and CRP $>150 \mathrm{mg} / \mathrm{L}$ (93.1\% and $26.3 \%$ ). The predictive performance was comparable only for albumin $<33 \mathrm{~g} / \mathrm{L}$ and NLR $\geq 5.1$; although moderate by both variables, the former characteristic demonstrated higher specificity but lower sensitivity for predicting 
myocardial injury and high inflammatory responses, was indicative for prolonged LOS but not for in-hospital death (Table 4).

Next we determined whether the combined use of the NLR and albumin level measured on admission can improve the prediction of postoperative outcomes. On admission, hypoalbuminaemia $(<33 \mathrm{~g} / \mathrm{L})$ was observed in $168(40.5 \%)$ patients, NLR $\geq 5.1$ in $275(66.3 \%)$ and both features, elevated NLR and low albumin, in 133 (32.0\%) subjects. Compared to either a high NLR or low albumin level, presence of both these characteristics was a more specific and slightly more accurate predictor of postoperative myocardial injury and high inflammatory responses. However, NLR>8.5 was a strong predictor of in-hospital death and prolonged LOS was predicted better by low albumin alone (Table 4). Multivariate analyses (adjusted for all the same above mentioned conditions) showed that patients with combination of these two factors compared to those with both admission NLR $<5.1$ and albumin $>33 \mathrm{~g} / \mathrm{L}$ had a very high risk of postoperative myocardial injury (OR11.54, 95\%CI 3.27 - 40.77, $\mathrm{p}=0.000$ ) and inflammatory complications with CRP>100 mg/L (OR 10.94, 95\%CI 4.58 - 22.89, $\mathrm{p}=0.000)$ or $\mathrm{CRP}>150 \mathrm{mg} / \mathrm{L}$ (OR 9.71, 95\%CI 3.86 24.42, $p=0.000$ ). ROC characteristics curves for predicting in-hospital mortality, postoperative myocardial injury and high inflammatory response using elevated NLR, low albumin and combination of both parameters are depicted in Figure 3.

\section{Validation of admission NLR as a risk prediction factor}

Patients in the validation dataset comparing to those in the test dataset were older ( +3.3 year), had a higher prevalence of CKD $(43.2 \%$ vs. $19.0 \%)$ and dementia $(27.8 \%$ vs.17.6\%), but there were no differences in other comorbidities, including CVD $(66.3 \%)$, history of stroke or transient ischaemic attack $(19.7 \%)$, type 2 DM (16.4\%), COPD, $(11.0 \%)$ and Parkinson's disease $(4.6 \%)$; the proportions of current $(5.4 \%)$ and former $(10.0 \%)$ smokers and alcohol over-users $(9.5 \%)$ were lower. Postoperatively myocardial injury (cTnI $>0.06 \mu \mathrm{g} / \mathrm{L})$ was observed in $27.2 \%(\mathrm{n}=80)$ of patients, a high inflammatory response with CRP>100 mg/L) in $60.2 \%(\mathrm{n}=177)$ and with CRP $>150 \mathrm{mg} / \mathrm{L}$ in $38.1 \% \quad(\mathrm{n}=112)$, a prolonged LOS (>10days) in 31.6\% (n=93) patients; $49 \%(n=97)$ of patients admitted from home $(n=198)$ have been discharged to a permanent RCF, and the in-hospital death rate was $4.8 \%(n=14)$.

When the admission NLR cut-off of $\geq 5.1$ derived from the test dataset was applied to the validation dataset it showed significant and similar predictive value for postoperative cTnI rise (AUC 0.684, sensitivity $77.9 \%$, NPV $82.7 \%$ ), for CRP $>100 \mathrm{mg} / \mathrm{L}$ (AUC 0.632, sensitivity 79.1\%, NPV 72.7\%), for CRP $>150 \mathrm{mg} / \mathrm{L}$ (AUC 0.639, sensitivity 89.1\%, NPV $88.7 \%$ ) and in-hospital death (AUC 0.700, sensitivity 92.9\%, NPV 99.0\%). NLR $\geq 5.1$ was also moderately predictive for LOS $>10$ days (AUC 0.572, sensitivity $51.0 \%$, NPV $69.2 \%$ ) and for being discharge to a RCF (AUC 0.594, sensitivity 72.2\%, NPV 63.5\%). Admission NLR $>8.5$ was a strong predictor of fatal outcome (AUC 0.801, sensitivity $89.6 \%$, specificity 70.6\%, NPV 98.7\%).

Table 4. Predictive value of selected preoperative parameters in detection poorer outcomes in orthogeriatric patients

\begin{tabular}{|c|c|c|c|c|c|c|c|}
\hline Variable & ROC & Sensitivity, $\%$ & Specificity, $\%$ & PPV, $\%$ & NPV, $\%$ & Accuracy rate, $\%$ & P value \\
\hline \multicolumn{8}{|c|}{ Post operative myocardial injury } \\
\hline NLR $>5.1$ & 0.738 & 86.7 & 38.5 & 23.8 & 92.9 & 47.2 & 0.000 \\
\hline Albumin $<33 \mathrm{~g} / \mathrm{L}$ & 0.774 & 72.4 & 67.2 & 33.1 & 91.5 & 68.1 & 0.000 \\
\hline NLR $>5.1+$ Albumin $<33 g / L$ & 0.774 & 64.0 & 75.4 & 36.6 & 90.4 & 73.4 & 0.000 \\
\hline \multicolumn{8}{|c|}{ Post operative CRP>100 mg/L } \\
\hline NLR $>5.1$ & 0.659 & 80.0 & 46.3 & 58.2 & 71.2 & 62.6 & 0.000 \\
\hline Albumin $<33 \mathrm{~g} / \mathrm{L}$ & 0.708 & 58.7 & 76.6 & 70.2 & 66.4 & 68.0 & 0.000 \\
\hline NLR $>5.1+$ Albumin $<33 g / L$ & 0.711 & 50.5 & 85.0 & 75.9 & 64.8 & 68.4 & 0.000 \\
\hline \multicolumn{8}{|c|}{ Post operative CRP>150 mg/L } \\
\hline NLR $>5.1$ & 0.664 & 85.3 & 42.1 & 40.0 & 86.3 & 55.6 & 0.000 \\
\hline Albumin $<33 \mathrm{~g} / \mathrm{L}$ & 0.678 & 62.3 & 69.5 & 48.2 & 80.2 & 67.2 & 0.000 \\
\hline NLR $>5.1+$ Albumin $<33 \mathrm{~g} / \mathrm{L}$ & 0.680 & 54.3 & 77.9 & 52.6 & 79.0 & 70.5 & 0.000 \\
\hline \multicolumn{8}{|c|}{ LOS $>10$ days } \\
\hline NLR $>5.1$ & 0.554 & 66.8 & 34.3 & 51.3 & 50.0 & 50.8 & 0.806 \\
\hline Albumin $<33 \mathrm{~g} / \mathrm{L}$ & 0.611 & 49.5 & 69.3 & 62.5 & 57.0 & 59.2 & 0.000 \\
\hline NLR $>5.1+$ Albumin $<33 g / L$ & 0.592 & 38.4 & 74.5 & 60.9 & 53.9 & 56.1 & 0.005 \\
\hline \multicolumn{8}{|c|}{ In-hospital death } \\
\hline NLR $>8.5$ & 0.847 & 90.0 & 68.6 & 6.6 & 99.6 & 69.1 & 0.000 \\
\hline Albumin $<33 \mathrm{~g} / \mathrm{L}$ & 0.765 & 70.0 & 60.3 & 4.2 & 98.8 & 60.6 & 0.053 \\
\hline NLR $>8.5+$ Albumin $<33 \mathrm{~g} / \mathrm{L}$ & 0.792 & 38.8 & 89.8 & 63.3 & 76.4 & 73.9 & 0.000 \\
\hline
\end{tabular}




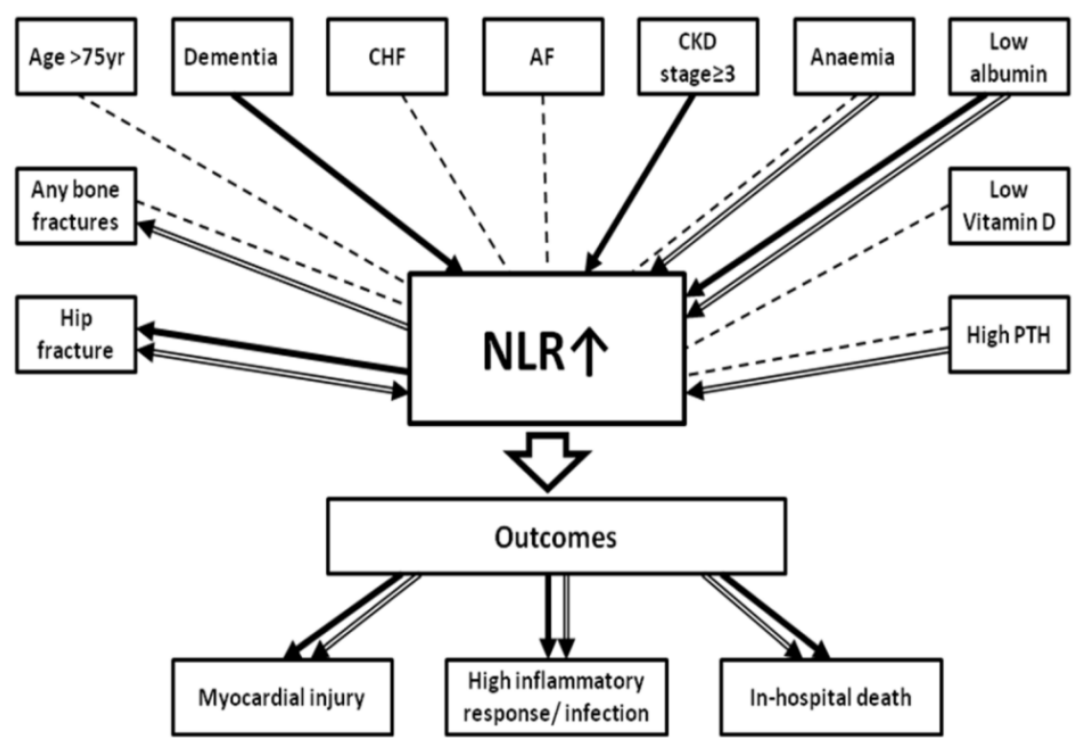

Figure 2. Associations between admission neutrophil to lymphocyte ratio (NLR), medical conditions, presence of fracture and short-term outcomes in orthogeriatric patients. Significant associations found in univariate analyses are shown in dot lines. Independent associations revealed by multivariate analyses are shown in bold (with NLR as a continuous variable) and in double-line (with NLR $\geq 5$ ). Arrow indicates the dependent variable. Higher admission NLR (both as a continuous and a categorical variable) is an independent indicator of hip fracture presence and risk factor of poorer outcomes; NLR $\geq 5$ is an independent indicator of any fracture. Dementia, hypoalbuminaemia and CKD $\geq 3$ stage are the independent correlates of higher preoperative NLR as a continuous variable; independent correlates of admission NLR $\geq 5.1$ are presence of hip fracture, lower levels of albumin and haemoglobin and elevated PTH concentration. Abbreviations: CHF, chronic heart failure; AF, atrial fibrillation; CKD $\geq 3$, chronic kidney disease (estimated glomerular filtration rate $<60 \mathrm{ml} / \mathrm{min} / 1.73 \mathrm{~m}^{2}$ ); Anaemia, haemoglobin<120g/L; Low albumin, <33g/L; Low vitamin D, serum 25-hydroxyvitamin D <25nmol/L; High PTH, parathyroid hormone>6.8pmol/L.
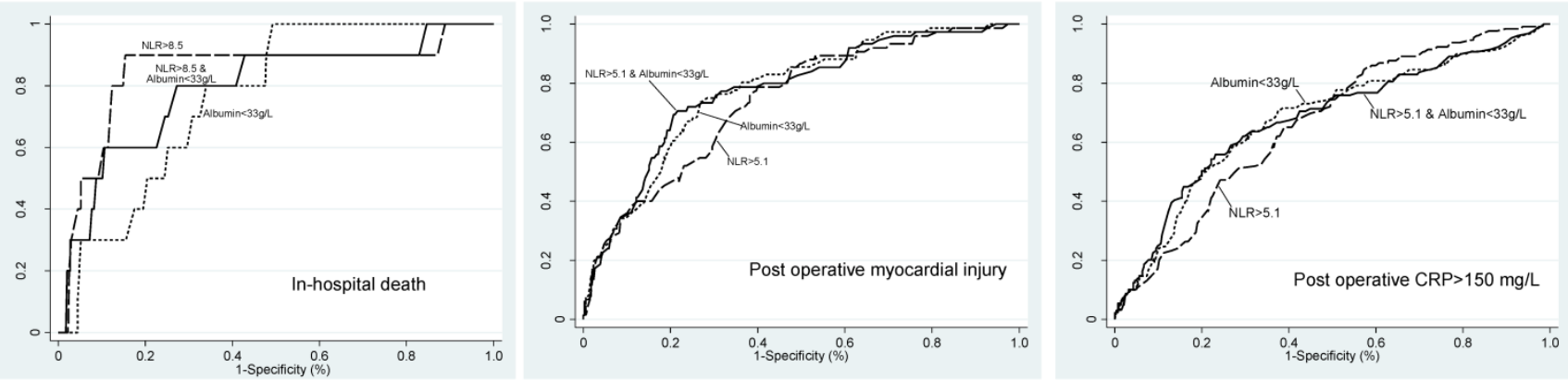

Figure 3. Receiver operating characteristics curves for predicting in-hospital mortality, postoperative myocardial injury with troponin I rise and high inflammatory response with CRP>150 mg/L. NLR, neutrophil to lymphocyte ratio; CRP, C-reactive protein.

\section{Discussion}

\section{Main findings}

In orthogeriatric patients at the time of hospital admission higher NLR (analysed both as a continuous and categorical variable) is: (1) an independent indicator of HF presence (although a variety of medical conditions affect NLR), and (2) an independent risk factor and modest predictor of poorer short-term postoperative outcomes such as myocardial injury (identified by cTnI rise), inflammatory complications (with high CRP levels), and in-hospital mortality (Figure 2). To our best knowledge, these results are the first to show that higher preoperative NLR, a widely available and inexpensive marker, may be helpful in improving the prognosis of elderly patients undergoing orthopaedic treatment.

\section{NLR, comorbidities and fractures}

In agreement with many studies [33, 65-67] in our univariate analyses, admission NLR was significantly associated with 10 variables: age $>75$ years, presence of any fracture, dementia, $\mathrm{AF}, \mathrm{CHF}$, CKD $\geq 3$ stage, anaemia, vitamin $\mathrm{D}$ deficiency, hyperparathyroidism and hypoalbuminaemia. Multivariate regression revealed only three variables, dementia, hypoalbuminaemia and $\mathrm{CKD} \geq 3$ stage, as independent determinants of higher preoperative NLR as a continuous variable; presence of HF showed borderline significance $(p=0.060)$. Independent determinants of admission NLR $\geq 5.1$ were presence of $\mathrm{HF}$, lower levels of albumin and haemoglobin and 
elevated serum PTH concentration. On the other hand, the analyses demonstrated a robust and independent association of higher NLR on admission and presence of fracture. There was a dose-graded relationship between presence of fracture, especially $\mathrm{HF}$, and levels of NLR categorized as tertiles. The crude odds ratios (OR) for presence of HF were 3.14 for NLR 5.1-8.5 (second tertile) and 4.93 for NLR>8.5 (third tertile), the ORs for any fracture were 1.75 and 2.62, respectively. Adjusted ORs (multivariate regression analyses), demonstrated a 3.11- and 1.74-fold increases in presence of HF or any fracture, respectively, when patients with NLR $\geq 5.1$ were compared with those in the first tertile.

In patients with a fracture, the cause (-s) of elevated NLR at admission may be multifactorial and related to a variety of pre-fracture co-morbid conditions, a concurrent clinical or subclinical infection, as well as to the responsive process to fracture per se. The association of fractures with higher NLR, a marker of dysregulated immune system and chronic inflammation, is in line with an increasing body of evidence linking immune status/low-grade inflammation (affecting both process - osteogenesis and bone resorption) with bone homeostasis and, consequently, with pathogenesis of osteoporosis [68-76] and higher fracture rates [77, 78]. Several recent studies demonstrated that NLR levels are significantly elevated in the elderly with osteoporosis and inversely correlated with BMD [79-81]. In other words, elevated NLR, an indicator of a systemic inflammatory-immunological process, not merely reflects a response to fracture and/or infection (in some patients at admission) but appears to be a significant factor linked to osteoporotic fractures.

\section{NLR and short-term outcomes}

The high incidence of concurrent medical comorbidities amongst orthogeriatric patients emphasises the importance of identification of vulnerable persons, recognition of potentially reversible risk factors and preoperative stabilisation. However, little is known about preoperative markers that can identify orthogeriatric patients at high risk of adverse outcomes. Most studies focussed on preoperative predictors of mortality in HF patients $[15,19,25,82-86]$. The prognostic role of preoperative NLR has not been systematically investigated in orthopaedic surgery, in contrast to that in patients with cancer, CVD, AF, DM, inflammatory diseases, chronic renal and hepatic failure.

In this study, it was demonstrated that higher NLR at admission not only correlates with presence of fracture and comorbidities but also closely relates to key adverse outcomes - postoperative myocardial injury, high inflammatory response and in-hospital death. The incidence of these three outcomes in our cohort was consistent with data reported in the literature. In our cohort which included both emergency and elective surgery patients, postoperative myocardial injury (diagnosed with an elevated cTnI measurement) occurred in $18.1 \%$. Perioperative cTnI elevation, the most common cardiovascular complication associated with significant morbidity and mortality [57, 87-89], was reported in $8 \%$ of adults undergoing major noncardiac surgery [57], in $19 \%$ of aged $>60$ years after noncardiac surgery [87], in $17 \%$ of subjects undergoing major orthopaedic surgery [5], in $22 \%$ $52.9 \%$ after emergency orthopaedic operations [2], and in $26.7 \%-39.0 \%$ of elderly HF patients [55, 56, 90].

Increased inflammatory response as measured by CRP, an acute-phase protein, is well known as a useful indicator of infection after operative fracture treatment and a major predictor of mortality in the elderly [91, 92]. In this study, after the $3^{\text {rd }}$ postoperative day $\mathrm{CRP}>100 \mathrm{mg} / \mathrm{L}$ was found in $48.2 \%$ of patients and CRP $>150 \mathrm{mg} / \mathrm{L}$ in $31.1 \%$. Previous research has shown that infective complications occur primarily in patients with persistent elevation and/or second rise in CRP concentrations (CRP>96 mg/L) after the first 3 postoperative days [62]. Postoperative infections complicating HF surgery have been reported in $8.9 \%-61 \%$ [10, 93-97] and were associated (particularly deep wound and chest infections) with delirium, increased length of hospital stay, 30-day and 1-year mortality [2, 10, 98]. The increased susceptibility of orthogeriatric patients to postoperative infective complications, one of the main factors affecting outcomes, is, at least partially, a result of age-related decline and dysregulation in immune functions [99-103]. Of note, although both NLR and CRP are well recognized inflammatory biomarkers and both increase following the elevation of circulating IL-6, which is produced by several types of cells (monocytes, macrophages and endothelial cells), other mechanisms underlying the development of a high NLR and elevated CRP differ. Whereas the production of CRP in human hepatocytes is mainly induced by circulating IL-6, lymphocytes play a central role in the immune reaction and NLR is a marker of systemic inflammation representative of innate and adaptive immunity. Not surprisingly, therefore, patients with a high NLR do not always have an elevated CRP as we observed in our cohort on admission, but elevated preoperative NLR indicates predisposition to postoperative infective complications with a high CRP.

In-patient mortality in our study was $2.4 \%(6.0 \%$ for HF patients) which is compatible with that in other 
centres. Reported short-term mortality for HF ranged between $1.14-4.6 \%$ [104, 105] - 10.9\% [106] and 13.3\% [16], but reaches $43 \%$ in patients with postoperative chest infection and $65 \%$ in patients with acute heart failure [2].

We observed a dose-graded relationship between increasing admission levels of NLR and the proportion of patients with postoperative myocardial injury, high inflammatory markers and fatal outcomes. Compared to patients with NLR $<5.1$, patients with NLR 5.1-8.5 had a 2.6-fold higher risk for developing postoperative myocardial injury and about 2.5- fold higher risk for a high inflammatory response, while in subjects with NLR>8.5 these risks were 5.9 and 4.5-6.7-times higher, respectively. Patients with admission NLR>8.5 had a 9.7 times higher chance of dying in the hospital compared to patients with NLR 5.1-8.5 (no deaths occurred in patients with NLR<5.1). Although in our study 10 patients who died in hospital do not provide good statistical power, all of them had admission NLR $\geq 5$ and 9 subjects had NLR $>8.5 ; 14$ patients with HF and fatal outcome in the validation cohort demonstrated similar NLR patterns.

In patients with $N L R \geq 5.1$ at admission the increased risks of postoperative myocardial injury and high inflammatory response persisted after accounting for multiple confounding factors known to be associated with postoperative complications and death; similarly NLR>8.5 was an independent and significant predictor of a fatal outcome. In other words, the risks of poor outcomes were dependent on the degree of the NLR elevation but independent of preoperative cardiovascular, metabolic, renal, nutritional and behavioural factors associated with adverse outcomes (as showed the multiple logistic regression analyses).

Forget et al. [50] reported that the preoperative NLR level did not predict short-term outcomes in HF patients. However, our data which identified higher NLR at admission as a significant risk factor for unfavourable outcomes in orthogeriatric patients is consistent with numerous studies demonstrating a strong association between elevated NLR levels and increased mortality in different cardiovascular, noncardiac and malignant diseases [28, 31-34, 67]. High NLR was found to be a significant predictor of mortality and worse outcomes in patients with acute coronary syndromes [32, 107], advanced heart failure [38], different cancers [29, 30, 108-110], in elderly patients who have underwent major vascular [111], abdominal [27] and lung cancer surgery [112].

Interestingly, although different factors were independently associated with presence of fracture and specific outcomes, elevated $\operatorname{NLR}(\geq 5.1)$ and low albumin $(<33 \mathrm{~g} / \mathrm{L})$ on admission were the only two independent variables associated with presence of any fracture, HF, as well as with poorer outcomes. The other independent factors for any fracture and HF were older age and dementia, for postoperative myocardial injury - AF and male sex, for high inflammatory responses - CKD, anaemia and elevated PTH (Table 3).

\section{Prognostic value of NLR on admission}

Although there is no consensus of what the normal NLR levels are, we identified $<5.1$ (upper limit in the first tertile) as the cut-off value to predict adverse outcomes. Of note, the threshold NLR $>5$ ("classical") has been used in many other studies [30, 109, 112]. We found that elevated NLR $\geq 5.1$ significantly differentiated subjects with poorer outcomes from the rest of the cohort, but only at a modest level (accuracy: 47.2\% for myocardial injury, $62.6 \%$ for postoperative CRP $>100 \mathrm{mg} / \mathrm{L}$ and $55.6 \%$ for postoperative $C R P>150 \mathrm{mg} / \mathrm{L}, \mathrm{p}=0.000$ in all cases). NLR>8.5 (third tertile) demonstrated a moderately better performance (accuracy: 69.5\%, 61.4\% and $69.8 \%$, respectively). NLR $\geq 5.1$ showed a considerably high sensitivity $(86.7 \%, 80.0 \%$ and $85.3 \%$, respectively) and negative predictive value (NPV, $92.9 \%, 71.2 \%$ and $86.3 \%$, respectively) indicating that these complications are unlikely in patients with a lower ratio. However, positive predictive value (PPV) was only $23.8 \%, 58.2 \%$ and $40.0 \%$, respectively, indicating that a higher NLR does not necessarily predict postoperative complications. NLR $>8.5$ had a moderately high sensitivity (90\%) and accuracy $(69.1 \%)$ for in-hospital death; the NPV was $99.6 \%$ showing that patients with a ratio lower than 8.5 were likely to survive, but NLR $>8.5$ does not predict a fatal outcome (PPV was only 6.6\%).

In this study, we have also evaluated twelve most widely recommended and used predictor markers for determining outcomes among orthogeriatric patients: age $>75$ years [113-115], dementia, presence of CVDs, AF, high white blood cell (WBC) count [19], low lymphocyte count [19, 23, $25,86,116,117,118]$, low serum albumin $[15,25$, 84-86, 117], anaemia/reduced haemoglobin levels $(\mathrm{Hb}<120 \mathrm{~g} / \mathrm{L})[15,18,19,22,82,83,94,119]$, vitamin $\mathrm{D}$ deficiency $(25(\mathrm{OH}) \mathrm{D}<25 \mathrm{nmol} / \mathrm{L})$ and insufficiency $(25(\mathrm{OH}) \mathrm{D}<50 \mathrm{nmol} / \mathrm{L})$, elevated PTH $(6.8 \mathrm{pmol} / \mathrm{L})$ $[115,120]$, and $C K D \geq 3$ stage. The performance of these markers, which have been suggested as independent prognostic factors for unfavourable outcomes in HF patients, was variable. For postoperative myocardial injury, for example, accuracy ranged from 35.0\% $(\mathrm{Hb}<120 \mathrm{~g} / \mathrm{L})$ to $75.5 \%(25(\mathrm{OH}) \mathrm{D}<25 \mathrm{nmol} / \mathrm{L})$ with sensitivity $89.5 \%$ and $9.2 \%$, respectively, and 
specificity $22.8 \%$ and $90.5 \%$, respectively. Similarly, other markers comparing to NLR, were either more specific (AF, dementia, CKD) but lacked sensitivity $(26.3 \%-32.9 \%)$ or, as age $>75$ years, had low specificity $(37.0 \%)$ and higher sensitivity (85.5\%). As NLR integrates two important and opposite immune pathways (neutrophils represent non-specific systemic inflammation and lymphocytes are a marker of the immune system physiological stress response) it is not surprisingly, that it performs better than absolute neutrophil and lymphocyte count separately. The predictive value examined using ROC curve analysis revealed that the highest discriminative ability for predicting in-hospital death has NLR $>8.5$ (AUC 0.847), albumin $<33 \mathrm{~g} / \mathrm{L}$ (AUC 0.765) and neutrophils $>8.0 \times 10^{9} / \mathrm{L}$ (AUC 0.720). Low admission albumin and elevated NLR were the two variables which demonstrated the highest prognostic values for postoperative myocardial injury and high inflammatory responses. On the whole, among the orthogeriatric patients, the NLR was superior to age and other routinely used admission characteristics, except hypoalbuminaemia, for determining these outcomes; only hypoalbuminaemia, in contrast to NLR, indicated LOS>10 days (ROC 0.594). However, patients with both elevated NLR and low albumin demonstrate only a moderately increased risk of adverse outcomes compared to subjects with either biomarker abnormal (Table 4; Figure 3).

Our validation study that included older patients with HF confirmed that admission NLR $\geq 5.1$ was a moderate predictor for patients' postoperative myocardial injury and high inflammatory responses but also for in-hospital death, LOS $>10$ days, and for being discharge to a RCF; NLR>8.5 was a strong predictor of fatal outcome.

Taking together, the admission NLR, except NLR>8.5 for in-hospital mortality, as well as all other above mentioned factors showed a modest/ relatively low performance to predict postoperative adverse outcomes (AUC < 0.700), and, therefore, should be considered mainly as risk factors than predictive ones. Clearly, NLR and other biomarkers to give reasonable prognostic information should be evaluated and interpreted in the context of a complete clinical assessment.

\section{Clinical implications}

Our results showing that higher NLR on admission is associated with fracture and worse outcomes suggest that NLR may be a useful additional biomarker for therapeutic selection and preventive intervention. Firstly, it is important to recognise that in the complex interplay of modifiable and non-modifiable factors which determine outcomes cTnI elevation, regardless of etiology, is associated with short- and long-term morbidity/mortality [2, 5, $54,56,57,87-89]$. The clinical relevance of preoperative identification of subjects with a high risk of this serious and silent (asymptomatic in $>80 \%$ of patients) complication is further emphasized by the reports that beta-blockers, alfa-2 agonists, calcium channel blockers, statins, and aspirin can prevent postoperative myocardial injury and reduce the risk of mortality [121-124]. Secondly, although this study was not designed to assess clinically apparent infection, elevated NLR $(\geq 5.1)$ on admission, indicates a high probability of perioperative infectious complications and might be useful when considering empirical antibiotic therapy. Although a higher NLR on admission could be an initiative for preventive treatment, whether patients with elevated NLR may benefit from preoperative cardiovascular medications and/or antibiotics must be elucidated. Thirdly, NLR>8.5 which was most discriminatory for survival may be (in conjunction with a comprehensive clinical assessment) helpful in preoperative predicting a fatal outcome and aid decision making with regard to operative plan. Fourthly, our findings showed that in orthogeriatric patients the systemic inflammatory-immunological process as indicated by elevated NLR may be an important contributor to the pathogenesis of osteoporotic fractures and other age-related diseases, rather than only a secondary reflection of fracture and/or concurrent infection. In other words, higher NLR which represents age-related changes in the immune system (immunoscenescence, $[125,126]$ ) and chronic inflammation, a phenomenon known as "inflamm-ageing" [127, 128], reflects and is influenced by a variety of age-related co-morbid conditions and fractures. Therefore, it appears that NLR $\geq 5.1$, an easily obtained clinical test, as a global index of inflammatory-immunological status may be a useful marker for screening and preventing multimorbidity including risk of osteoporotic fracture in older adults. However, it should be emphasised that although the elevated NLR at admission demonstrates high statistical significance as an independent risk factor for poorer outcomes, its prognostic value in relation to individual patients is modest (but superior to the majority of other recommended predictors) and it does not indicate the type of possible adverse outcome. Obviously, any decision on prophylactic treatment (use of antibiotics and/or cardioprotecive drugs) requires full clinical assessment. Further investigations of the predictive value of NLR in orthogeriatric patients are needed to provide more insight into the pathophysiology of its elevation as well as in specific and individualised perioperative 
therapeutic interventions to improve outcomes for these complex patients.

\section{Limitations and Strength}

Several limitations of this study should be considered. First, because our study is observational, the inference of a causal relationship between admission NLR and outcomes is limited. Second, as we have included all orthogeriatric patients, without any exclusion criterion, the contribution of age-related impairment of the immune system, stress response to the fracture, active preoperative infection, and/or combination of these factors to elevated NLR was difficult to differentiate and determine. However, the substantial heterogeneity of our cohort is typical and reflects the real-world clinical practice. Third, the rate of in-hospital mortality was low, so caution is necessary when interpreting this result. Finally, it was a single-center study mainly of Caucasians and, therefore, may not necessarily translate to other centers with differing management practices and be representative of other racial and ethnic populations. The strengths of this prospective study are that it (1) focused on all orthogeriatric patients whereas previous studies have targeted selected patient groups, mainly with $\mathrm{HF}$, (2) included multiple NLR-affecting factors, (3) analysed demographic, co-morbid and laboratory variables previously implicated as admission markers of poorer outcomes, but in most studies not assessed in the same patients in relation to postoperative outcome prognosis, and (5) validated the results in a cohort of HF patients. Of note, in multivariate regression analyses the variance inflation factor in all models presented in Tables 2 and 3 was less than 1.3, indicating that the amount of multicolinearity was no significant.

\section{Conclusions}

In orthogeriatric patients, the high NLR $(\geq 5.1)$ on admission is an independent indicator of fracture presence, a significant risk factor and moderate predictor of poorer postoperative outcomes including myocardial injury, high inflammatory response/infection and in-hospital death. This simple and inexpensive biomarker could be used for risk stratification and individualized perioperative management. Multi-centre prospective studies are required to explore whether interventions to decrease NLR levels reduces fractures and improves outcomes.

\section{Competing Interests}

The authors have declared that no competing interest exists.

\section{References}

[1] Boyd CM, et al. Guiding principles for the care of older adults with multimorbidity: an approach for clinicians: American Geriatrics Society Expert Panel on the Care of Older Adults with Multimorbidity. J Am Geriatr Soc 2012;60: E1-E25.

[2] Chong CP, van Gaal WJ, Savige J, and Lim WK. Cardiac injury and troponin testing after orthopaedic surgery. Injury 2011;42: 855-63.

[3] Cullen MW, Reeder GS, Farkouh ME, Kopecky SL, Smars PA, Behrenbeck TR, et al. Outcomes in patients with chest pain evaluated in a chest pain unit: the chest pain evaluation in the emergency room study cohort. Am Heart J 2011;161: 871-7.

[4] Huddleston JM, Gullerud RE, Smither F, Huddleston PM, Larson DR, Phy MP, et al. Myocardial infarction after hip fracture repair: a population-based study. J Am Geriatr Soc 2012;60: 2020-6.

[5] Oberweis BS, Smilowitz NR, Nukala S, Rosenberg A, Xu J, Stuchin S, et al. Relation of perioperative elevation of troponin to long-term mortality after orthopedic surgery. Am J Cardiol 2015;115: 1643-8.

[6] Smith T, Pelpola K, Ball M, Ong A, and Myint PK. Pre-operative indicators for mortality following hip fracture surgery: a systematic review and meta-analysis. Age Ageing 2014;43: 464-71.

[7] Evans RP. Surgical site infection prevention and control: an emerging paradigm. J Bone Joint Surg Am 2009;91 Suppl 6: 2-9.

[8] Acklin YP, Widmer AF, Renner RM, Frei R, and Gross T. Unexpectedly increased rate of surgical site infections following implant surgery for hip fractures: problem solution with the bundle approach. Injury 2011;42: 209-16.

[9] Baehl S, Garneau H, Le Page A, Lorrain D, Viens I, Svotelis A, et al. Altered neutrophil functions in elderly patients during a 6-month follow-up period after a hip fracture. Exp Gerontol 2015;65: 58-68.

[10] Dovjak P, Iglseder B, Mikosch P, Gosch M, Muller E, Pinter G, et al. Treatment and prevention of postoperative complications in hip fracture patients: infections and delirium. Wien Med Wochenschr 2013;163: 448-54.

[11] Friedman SM and Mendelson DA. Epidemiology of fragility fractures. Clin Geriatr Med 2014;30: 175-81.

[12] Kirkland KB, Briggs JP, Trivette SL, Wilkinson WE, and Sexton DJ. The impact of surgical-site infections in the 1990s: attributable mortality, excess length of hospitalization, and extra costs. Infect Control Hosp Epidemiol 1999;20: 725-30.

[13] Palmer SJ, Parker MJ, and Hollingworth W. The cost and implications of reoperation after surgery for fracture of the hip. J Bone Joint Surg Br 2000;82: 864-6.

[14] Talsnes O, Hjelmstedt F, Dahl OE, Pripp AH, and Reikeras O. Clinical and biochemical prediction of early fatal outcome following hip fracture in the elderly. Int Orthop 2011;35: 903-7.

[15] Laulund AS, Lauritzen JB, Duus BR, Mosfeldt M, and Jorgensen HL. Routine blood tests as predictors of mortality in hip fracture patients. Injury 2012;43: 1014-20.

[16] Hu F, Jiang C, Shen J, Tang P, and Wang Y. Preoperative predictors for mortality following hip fracture surgery: a systematic review and meta-analysis. Injury 2012;43: 676-85.

[17] Mosfeldt M, Pedersen OB, Riis T, Worm HO, Mark S, Jorgensen HL, et al. Value of routine blood tests for prediction of mortality risk in hip fracture patients. Acta Orthop 2012;83: 31-5.

[18] Kovar FM, Endler G, Wagner OF, and Jaindl M. Basal haemoglobin levels as prognostic factor for early death in elderly patients with a hip fracture - A twenty year observation study. Injury 2015;46: 1018-22.

[19] Bhaskar D and Parker MJ. Haematological indices as surrogate markers of factors affecting mortality after hip fracture. Injury 2011;42: 178-82.

[20] Norring-Agerskov D, Laulund AS, Lauritzen JB, Duus BR, van der Mark S, Mosfeldt M, et al. Metaanalysis of risk factors for mortality in patients with hip fracture. Dan Med J 2013;60: A4675.

[21] Toson B, Harvey LA, and Close JC. The ICD-10 Charlson Comorbidity Index predicted mortality but not resource utilization following hip fracture. J Clin Epidemiol 2015;68: 44-51.

[22] Maxwell MJ, Moran CG, and Moppett IK. Development and validation of a preoperative scoring system to predict 30 day mortality in patients undergoing hip fracture surgery. Br J Anaesth 2008;101: 511-7.

[23] Koval KJ, Maurer SG, Su ET, Aharonoff GB, and Zuckerman JD. The effects of nutritional status on outcome after hip fracture. J Orthop Trauma 1999;13: 164-9.

[24] Abrahamsen B, van Staa T, Ariely R, Olson M, and Cooper C. Excess mortality following hip fracture: a systematic epidemiological review. Osteoporos Int 2009;20: 1633-50.

[25] Kumar V, Alva A, Akkena S, Jones M, Murphy PN, and Clough T. Are albumin and total lymphocyte count significant and reliable predictors of mortality in fractured neck of femur patients? Eur J Orthop Surg Traumatol 2014;24: 1193-6.

[26] Zahorec R. Ratio of neutrophil to lymphocyte counts--rapid and simple parameter of systemic inflammation and stress in critically ill. Bratisl Lek Listy 2001;102: 5-14.

[27] Vaughan-Shaw PG, Rees JR, and King AT. Neutrophil lymphocyte ratio in outcome prediction after emergency abdominal surgery in the elderly. Int J Surg 2012;10: 157-62 
[28] Tan TP, Arekapudi A, Metha J, Prasad A, and Venkatraghavan L. Neutrophil-lymphocyte ratio as predictor of mortality and morbidity in cardiovascular surgery: a systematic review. ANZ J Surg 2015;85: 414-9.

[29] Malietzis G, Giacometti M, Kennedy RH, Athanasiou T, Aziz O, and Jenkins JT. The emerging role of neutrophil to lymphocyte ratio in determining colorectal cancer treatment outcomes: a systematic review and meta-analysis. Ann Surg Oncol 2014;21: 3938-46.

[30] Paramanathan A, Saxena A, and Morris DL. A systematic review and meta-analysis on the impact of pre-operative neutrophil lymphocyte ratio on long term outcomes after curative intent resection of solid tumours. Surg Oncol 2014;23: 31-9.

[31] Templeton AJ, McNamara MG, Seruga B, Vera-Badillo FE, Aneja P, Ocana A, et al. Prognostic role of neutrophil-to-lymphocyte ratio in solid tumors: a systematic review and meta-analysis. J Natl Cancer Inst 2014;106: dju124.

[32] Tamhane UU, Aneja S, Montgomery D, Rogers EK, Eagle KA, and Gurm HS. Association between admission neutrophil to lymphocyte ratio and outcomes in patients with acute coronary syndrome. Am J Cardiol 2008;102: 653-7.

[33] Bhat T, Teli S, Rijal J, Bhat H, Raza M, Khoueiry G, et al. Neutrophil to lymphocyte ratio and cardiovascular diseases: a review. Expert Rev Cardiovasc Ther 2013;11: 55-9.

[34] Balta S, Demirkol S, Unlu M, Arslan Z, and Celik T. Neutrophil to lymphocyte ratio may be predict of mortality in all conditions. Br J Cancer 2013;109: 3125-6.

[35] Ijsselmuiden AJ, Musters RJ, de Ruiter G, van Heerebeek L, Alderse-Baas F, van Schilfgaarde $\mathrm{M}$, et al. Circulating white blood cells and platelets amplify oxidative stress in heart failure. Nat Clin Pract Cardiovasc Med 2008;5: 811-20.

[36] Azab B, Zaher M, Weiserbs KF, Torbey E, Lacossiere K, Gaddam S, et al. Usefulness of neutrophil to lymphocyte ratio in predicting short- and long-term mortality after non-ST-elevation myocardial infarction. Am J Cardiol 2010;106: 470-6.

[37] Tasal A, Erturk M, Uyarel H, Karakurt H, Bacaksiz A, Vatankulu MA, et al. Utility of the neutrophil to lymphocyte ratio for predicting in-hospital mortality after levosimendan infusion in patients with acute decompensated heart failure. J Cardiol 2014;63: 418-23.

[38] Uthamalingam S, Patvardhan EA, Subramanian S, Ahmed W, Martin W, Daley $\mathrm{M}$, et al. Utility of the neutrophil to lymphocyte ratio in predicting long-term outcomes in acute decompensated heart failure. Am J Cardiol 2011;107: 433-8.

[39] Wang X, Zhang G, Jiang X, Zhu H, Lu Z, and Xu L. Neutrophil to lymphocyte ratio in relation to risk of all-cause mortality and cardiovascular events among patients undergoing angiography or cardiac revascularization: a meta-analysis of observational studies. Atherosclerosis 2014;234: 206-13.

[40] Celikbilek A, Ismailogullari S, and Zararsiz G. Neutrophil to lymphocyte ratio predicts poor prognosis in ischemic cerebrovascular disease. J Clin Lab Anal 2014;28: 27-31.

[41] Erturk M, Cakmak HA, Surgit O, Celik O, Aksu HU, Akgul O, et al. Predictive value of elevated neutrophil to lymphocyte ratio for long-term cardiovascular mortality in peripheral arterial occlusive disease. J Cardiol 2014;64: 371-6.

[42] Roxburgh CS and McMillan DC. Role of systemic inflammatory response in predicting survival in patients with primary operable cancer. Future Oncol 2010;6: 149-63.

[43] Yang JJ, Hu ZG, Shi WX, Deng T, He SQ, and Yuan SG. Prognostic significance of neutrophil to lymphocyte ratio in pancreatic cancer: a meta-analysis. World J Gastroenterol 2015;21: 2807-15

[44] Gungor B, Ozcan KS, Erdinler I, Ekmekci A, Alper AT, Osmonov D, et al. Elevated levels of RDW is associated with non-valvular atrial fibrillation. J Thromb Thrombolysis 2014;37: 404-10.

[45] Choi ES, Kim HS, and Han I. Elevated preoperative systemic inflammatory markers predict poor outcome in localized soft tissue sarcoma. Ann Surg Oncol 2014;21: 778-85.

[46] Jagdev SP, Gregory W, Vasudev NS, Harnden P, Sim S, Thompson D, et al. Improving the accuracy of pre-operative survival prediction in renal cell carcinoma with C-reactive protein. Br J Cancer 2010:103: 1649-56.

[47] Ramsey S, Lamb GW, Aitchison M, and McMillan DC. Prospective study of the relationship between the systemic inflammatory response, prognostic scoring systems and relapse-free and cancer-specific survival in patients undergoing potentially curative resection for renal cancer. BJU Int 2008;101: 959-63.

[48] Forget P, Dinant V, and De Kock M. Is the Neutrophil-to-Lymphocyte Ratio more correlated than C-reactive protein with postoperative complications after major abdominal surgery? PeerJ 2015;3: e713.

[49] Cook EJ, Walsh SR, Farooq N, Alberts JC, Justin TA, and Keeling NJ. Post-operative neutrophil-lymphocyte ratio predicts complications following colorectal surgery. Int J Surg 2007;5: 27-30.

[50] Forget P, Moreau N, Engel H, Cornu O, Boland B, De Kock M, et al. The neutrophil-to-lymphocyte ratio (NLR) after surgery for hip fracture (HF). Arch Gerontol Geriatr 2015;60: 366-71.

[51] Johnson DW, Jones GR, Mathew TH, Ludlow MJ, Doogue MP, Jose MD, et al. Chronic kidney disease and automatic reporting of estimated glomerular filtration rate: new developments and revised recommendations. Med J Aust 2012;197: 224-5

[52] Levey AS and Stevens LA. Estimating GFR using the CKD Epidemiology Collaboration (CKD-EPI) creatinine equation: more accurate GFR estimates, lower CKD prevalence estimates, and better risk predictions. Am J Kidney Dis 2010;55: 622-7.
[53] Voss B, Kurdi A, Skopec A, Saleh J, El-Othmani MM, Lane JM, et al. Renal and Gastrointestinal Considerations in Joint Replacement Surgery. J Nat Sci 2015;1: e46.

[54] Fisher AA, Southcott EK, Srikusalanukul W, Davis MW, Hickman PE, Potter $\mathrm{JM}$, et al. Relationships between myocardial injury, all-cause mortality, vitamin D, PTH, and biochemical bone turnover markers in older patients with hip fractures. Ann Clin Lab Sci 2007;37: 222-32.

[55] Fisher AA, Southcott EN, Goh SL, Srikusalanukul W, Hickman PE, Davis MW, et al. Elevated serum cardiac troponin I in older patients with hip fracture: incidence and prognostic significance. Arch Orthop Trauma Surg 2008;128: 1073-9.

[56] Sandhu A, Sanders S, and Geraci SA. Prognostic value of cardiac troponins in elderly patients with hip fracture--a systematic review. Osteoporos Int 2013;24: $1145-9$.

[57] Khan J, Alonso-Coello P, and Devereaux PJ. Myocardial injury after noncardiac surgery. Curr Opin Cardiol 2014;29: 307-11.

[58] Larsson S, Thelander U, and Friberg S. C-reactive protein (CRP) levels after elective orthopedic surgery. Clin Orthop Relat Res 1992;237-42.

[59] Horst K, Hildebrand F, Pfeifer R, Koppen K, Lichte P, Pape HC, et al. Plate osteosynthesis versus hemiarthroplasty in proximal humerus fractures--does routine screening of systemic inflammatory biomarkers makes sense? Eur J Med Res 2015;20: 5.

[60] Pfafflin A and Schleicher E. Inflammation markers in point-of-care testing (POCT). Anal Bioanal Chem 2009;393: 1473-80.

[61] Lelubre C, Anselin S, Zouaoui Boudjeltia K, Biston P, and Piagnerelli M. Interpretation of C-reactive protein concentrations in critically ill patients. Biomed Res Int 2013;2013: 124021.

[62] Neumaier M and Scherer MA. C-reactive protein levels for early detection of postoperative infection after fracture surgery in 787 patients. Acta Orthop 2008;79: 428-32.

[63] Kraft CN, Kruger T, Westhoff J, Luring C, Weber O, Wirtz DC, et al. CRP and leukocyte-count after lumbar spine surgery: fusion vs. nucleotomy. Acta Orthop 2011;82: 489-93

[64] Lee JH, Lee JH, Kim JB, Lee HS, Lee DY, and Lee DO. Normal range of the inflammation related laboratory findings and predictors of the postoperative infection in spinal posterior fusion surgery. Clin Orthop Surg 2012;4: 269-77.

[65] Balta S, Celik T, Mikhailidis DP, Ozturk C, Demirkol S, Aparci M, et al. The Relation Between Atherosclerosis and the Neutrophil-Lymphocyte Ratio. Clin Appl Thromb Hemost 2015;

[66] Koza Y. Neutrophil-Lympocyte Ratio and Cardiovascular Diseases: An Update. Angiology 2015;

[67] Shao Q, Chen K, Rha SW, Lim HE, Li G, and Liu T. Usefulness of Neutrophil/Lymphocyte Ratio as a Predictor of Atrial Fibrillation: A Meta-analysis. Arch Med Res 2015;46: 199-206.

[68] Caetano-Lopes J, Canhao H, and Fonseca JE. Osteoimmunology--the hidden immune regulation of bone. Autoimmun Rev 2009;8: 250-5.

[69] Criscitiello C, Viale G, Gelao L, Esposito A, De Laurentiis M, De Placido S, et al. Crosstalk between bone niche and immune system: osteoimmunology signaling as a potential target for cancer treatment. Cancer Treat Rev 2015;41: 61-8.

[70] Danks L and Takayanagi H. Immunology and bone. J Biochem 2013;154: 29-39.

[71] Guerrini MM and Takayanagi H. The immune system, bone and RANKL. Arch Biochem Biophys 2014;561: 118-23.

[72] Mensah KA, Li J, and Schwarz EM. The emerging field of osteoimmunology. Immunol Res 2009;45: 100-13.

[73] Nakashima T and Takayanagi H. Osteoimmunology: crosstalk between the immune and bone systems. J Clin Immunol 2009;29: 555-67.

[74] Quinn JM and Saleh H. Modulation of osteoclast function in bone by the immune system. Mol Cell Endocrinol 2009;310: 40-51.

[75] Takayanagi H. Osteoimmunology: shared mechanisms and crosstalk between the immune and bone systems. Nat Rev Immunol 2007;7: 292-304.

[76] Takayanagi H, Osteoimmunology in 2014: Two-faced immunology-from osteogenesis to bone resorption. Nat Rev Rheumatol 2015;11: 74-6.

[77] Nakamura K, Saito T, Kobayashi R, Oshiki R, Oyama M, Nishiwaki T, et al. $\mathrm{C}$-reactive protein predicts incident fracture in community-dwelling elderly Japanese women: the Muramatsu study. Osteoporos Int 2011;22: 2145-50.

[78] Barbour KE, Lui LY, Ensrud KE, Hillier TA, LeBlanc ES, Ing SW, et al. Inflammatory markers and risk of hip fracture in older white women: the study of osteoporotic fractures. J Bone Miner Res 2014;29: 2057-64.

[79] Ozturk ZA, Yesil Y, Kuyumcu ME, Bilici M, Ozturk N, Yesil NK, et al. Inverse relationship between neutrophil lymphocyte ratio (NLR) and bone mineral density (BMD) in elderly people. Arch Gerontol Geriatr 2013;57: 81-5.

[80] Yilmaz H, Uyfun M, Yilmaz TS, Namuslu M, Inan O, Taskin A, et al. Neutrophil-lymphocyte ratio may be superior to C-reactive protein for predicting the occurrence of postmenopausal osteoporosis. Endocr Regul 2014:48: 25-33.

[81] Yu XY, Li XS, Li Y, Liu T, and Wang RT. Neutrophil-lymphocyte ratio is associated with arterial stiffness in postmenopausal women with osteoporosis. Arch Gerontol Geriatr 2015;61: 76-80.

[82] Gruson KI, Aharonoff GB, Egol KA, Zuckerman JD, and Koval KJ. The relationship between admission hemoglobin level and outcome after hip fracture. J Orthop Trauma 2002;16: 39-44.

[83] Halm EA, Wang JJ, Boockvar K, Penrod J, Silberzweig SB, Magaziner J. et al. The effect of perioperative anemia on clinical and functional outcomes in patients with hip fracture. J Orthop Trauma 2004;18: 369-74. 
[84] Pimlott BJ, Jones CA, Beaupre LA, Johnston DW, and Majumdar SR. Prognostic impact of pre-operative albumin on short-term mortality and complications in patients with hip fracture. Arch Gerontol Geriatr 2011;53: 90-4.

[85] Kieffer WK, Rennie CS, and Gandhe AJ. Preoperative albumin as a predictor of one-year mortality in patients with fractured neck of femur. Ann R Coll Surg Engl 2013;95: 26-8.

[86] O'Daly BJ, Walsh JC, Quinlan JF, Falk GA, Stapleton R, Quinlan WR, et al. Serum albumin and total lymphocyte count as predictors of outcome in hip fractures. Clin Nutr 2010;29: 89-93.

[87] van Waes JA, Nathoe HM, de Graaff JC, Kemperman H, de Borst GJ, Peelen LM, et al. Myocardial injury after noncardiac surgery and its association with short-term mortality. Circulation 2013;127: 2264-71.

[88] Levy M, Heels-Ansdell D, Hiralal R, Bhandari M, Guyatt G, Yusuf S, et al. Prognostic value of troponin and creatine kinase muscle and brain isoenzyme measurement after noncardiac surgery: a systematic review and meta-analysis. Anesthesiology 2011;114: 796-806.

[89] Devereaux PJ, Xavier D, Pogue J, Guyatt G, Sigamani A, Garutti I, et al. Characteristics and short-term prognosis of perioperative myocardial infarction in patients undergoing noncardiac surgery: a cohort study. Ann Intern Med 2011;154: 523-8.

[90] Dawson-Bowling S, Chettiar K, Cottam H, Worth R, Forder J, Fitzgerald-O'Connor I, et al. Troponin $\mathrm{T}$ as a predictive marker of morbidity in patients with fractured neck of femur. Injury 2008;39: 775-80.

[91] Forasassi C, Golmard JL, Pautas E, Piette F, Myara I, and Raynaud-Simon A. Inflammation and disability as risk factors for mortality in elderly acute care patients. Arch Gerontol Geriatr 2009;48: 406-10.

[92] Joseph B, Pandit V, Zangbar B, Kulvatunyou N, Hashmi A, Green DJ, et al. Superiority of frailty over age in predicting outcomes among geriatric trauma patients: a prospective analysis. JAMA Surg 2014;149: 766-72.

[93] Bateman L, Vuppala S, Porada P, Carter W, Baijnath C, Burman K, et al. Medical management in the acute hip fracture patient: a comprehensive review for the internist. Ochsner J 2012;12: 101-10.

[94] Carpintero P, Caeiro JR, Carpintero R, Morales A, Silva S, and Mesa M. Complications of hip fractures: A review. World J Orthop 2014;5: 402-11.

[95] Chia PH, Gualano L, Seevanayagam S, and Weinberg L. Outcomes following fractured neck of femurin an Australian metropolitan teaching hospital. Bone Joint Res 2013;2: 162-8.

[96] Fields AC, Dieterich JD, Buterbaugh K, and Moucha CS. Short-term complications in hip fracture surgery using spinal versus general anaesthesia. Injury 2015;46: 719-23.

[97] Johansson I, Athlin E, Frykholm L, Bolinder H, and Larsson G. Intermittent versus indwelling catheters for older patients with hip fractures. J Clin Nurs 2002;11: 651-6.

[98] Roche JJ, Wenn RT, Sahota O, and Moran CG. Effect of comorbidities and postoperative complications on mortality after hip fracture in elderly people: prospective observational cohort study. BMJ 2005;331: 1374

[99] Fulop T, Le Page A, Fortin C, Witkowski JM, Dupuis G, and Larbi A. Cellular signaling in the aging immune system. Curr Opin Immunol 2014;29: 105-11.

[100]Garcia-Alvarez F, Gonzalez P, Navarro-Zorraquino M, Larrad L, Garcia-Alvarez I, Pastor C, et al. Immune cell variations in patients with hip fracture. Arch Gerontol Geriatr 2008:46: 117-24

[101]Solana R, Tarazona R, Gayoso I, Lesur O, Dupuis G, and Fulop T, Innate immunosenescence: effect of aging on cells and receptors of the innate immune system in humans. Semin Immunol 2012;24: 331-41.

[102]Vester H, Huber-Lang MS, Kida Q, Scola A, van Griensven M, Gebhard F, et al. The immune response after fracture trauma is different in old compared to young patients. Immun Ageing 2014;11: 20.

[103]Wang GC and Casolaro V. Immunologic changes in frail older adults. Transl Med UniSa 2014;9: 1-6.

[104]Kammerlander C, Roth T, Friedman SM, Suhm N, Luger TJ, Kammerlander-Knauer U, et al. Ortho-geriatric service--a literature review comparing different models. Osteoporos Int 2010;21: S637-46.

[105]Tarrant SM, Hardy BM, Byth PL, Brown TL, Attia J, and Balogh ZJ. Preventable mortality in geriatric hip fracture inpatients. Bone Joint J 2014;96B: 1178-84.

[106]Wright DM, Blanckley S, Stewart GJ, and Copeland GP. The use of orthopaedic POSSUM as an audit tool for fractured neck of femur. Injury 2008;39: 430-5.

[107]Gibson PH, Cuthbertson BH, Croal BL, Rae D, El-Shafei H, Gibson G, et al. Usefulness of neutrophil/lymphocyte ratio as predictor of new-onset atrial fibrillation after coronary artery bypass grafting. Am J Cardiol 2010;105: 186-91.

[108]Guthrie GJ, Charles KA, Roxburgh CS, Horgan PG, McMillan DC, and Clarke SJ. The systemic inflammation-based neutrophil-lymphocyte ratio: experience in patients with cancer. Crit Rev Oncol Hematol 2013;88: 218-30.

[109]Peng B, Wang YH, Liu YM, and Ma LX. Prognostic significance of the neutrophil to lymphocyte ratio in patients with non-small cell lung cancer: a systemic review and meta-analysis. Int J Clin Exp Med 2015;8: 3098-106.

[110]Yang X, Huang Y, Feng JF, and Liu JS. Prognostic significance of neutrophil-tolymphocyte ratio in esophageal cancer: a meta-analysis. Onco Targets Ther 2015;8: 789-94

[111]Bhutta H, Agha R, Wong J, Tang TY, Wilson YG, and Walsh SR. Neutrophil-lymphocyte ratio predicts medium-term survival following elective major vascular surgery: a cross-sectional study. Vasc Endovascular Surg 2011;45: 227-31.

[112]Choi JE, Villarreal J, Lasala J, Gottumukkala V, Mehran RJ, Rice D, et al. Perioperative neutrophil:lymphocyte ratio and postoperative NSAID use as predictors of survival after lung cancer surgery: a retrospective study. Cancer Med 2015;4: 825-33.

[113]Holt G, Smith R, Duncan K, Finlayson DF, and Gregori A. Early mortality after surgical fixation of hip fractures in the elderly: an analysis of data from the scottish hip fracture audit. J Bone Joint Surg Br 2008;90: 1357-63.

[114]Lefaivre KA, Macadam SA, Davidson DJ, Gandhi R, Chan H, and Broekhuyse $\mathrm{HM}$. Length of stay, mortality, morbidity and delay to surgery in hip fractures. J Bone Joint Surg Br 2009;91: 922-7.

[115]Fisher AA, Srikusalanukul W, Davis MW, and Smith PN. Clinical profiles and risk factors for outcomes in older patients with cervical and trochanteric hip fracture: similarities and differences. J Trauma Manag Outcomes 2012;6: 2.

[116]Di Monaco M, Di Monaco R, Manca M, and Cavanna A. Positive association between total lymphocyte count and femur bone mineral density in hip-fractured women. Gerontology 2002;48: 157-61.

[117]Symeonidis PD and Clark D. Assessment of malnutrition in hip fracture patients: effects on surgical delay, hospital stay and mortality. Acta Orthop Belg 2006;72: 420-7.

[118]Aghdaii N, Ferasatkish R, Mohammadzadeh Jouryabi A, and Hamidi SH. Significance of preoperative total lymphocyte count as a prognostic criterion in adult cardiac surgery. Anesth Pain Med 2014;4: e20331.

[119]Potter LJ, Doleman B, and Moppett IK. A systematic review of pre-operative anaemia and blood transfusion in patients with fractured hips. Anaesthesia 2015;70: 483-500.

[120]Fisher A, Srikusalanukul W, Davis M, and Smith P. Hip fracture type: important role of parathyroid hormone (PTH) response to hypovitaminosis D. Bone 2010;47: 400-7.

[121]Cao L, Young N, Liu H, Silvestry S, Sun W, Zhao N, et al. Preoperative aspirin use and outcomes in cardiac surgery patients. Ann Surg 2012;255: 399-404.

[122]Daumerie G and Fleisher LA. Perioperative beta-blocker and statin therapy. Curr Opin Anaesthesiol 2008;21: 60-5.

[123]Poldermans D, Hoeks SE, and Feringa HH. Pre-operative risk assessment and risk reduction before surgery. J Am Coll Cardiol 2008;51: 1913-24.

[124]Task Force for Preoperative Cardiac Risk A. Perioperative Cardiac Management in Non-cardiac S, European Society of C, Poldermans D, Bax JJ, Boersma E, et al. Guidelines for pre-operative cardiac risk assessment and perioperative cardiac management in non-cardiac surgery. Eur Heart J 2009;30: 2769-812.

[125]Linehan E and Fitzgerald DC. Ageing and the immune system: focus on macrophages. Eur J Microbiol Immunol (Bp) 2015;5: 14-24.

[126]Panda A, Arjona A, Sapey E, Bai F, Fikrig E, Montgomery RR, et al. Human innate immunosenescence: causes and consequences for immunity in old age. Trends Immunol 2009;30: 325-33.

[127]Cevenini E, Monti D, and Franceschi C. Inflamm-ageing. Curr Opin Clin Nutr Metab Care 2013;16: 14-20.

[128]Franceschi C, Bonafe M, Valensin S, Olivieri F, De Luca M, Ottaviani E, et al. Inflamm-aging. An evolutionary perspective on immunosenescence. Ann N Y Acad Sci 2000;908: 244-54. 